Mitteilungen der Österreichischen Geographischen Gesellschaft, 152. Jg. (Jahresband), Wien 2010, S. 201-227

\title{
Die Veränderung von StaAtsgrenzen und ihre Folgen IM SLOWENISCH-ITALIENISCHEN GRENZRAUM
}

\author{
Peter ČEDE, Dieter FLECK und Gerhard Karl LIEB, alle Graz**
}

mit 7 Abb. und 2 Tab. im Text

\section{INHALT}

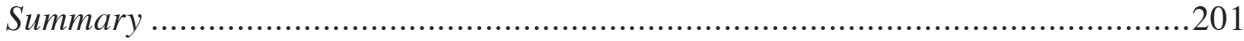

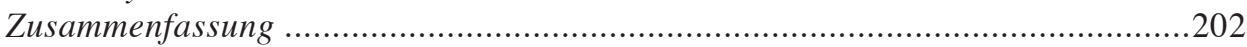

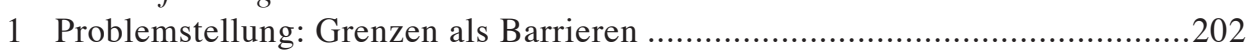

2 Die Veränderung von Grenzen und Territorien..........................................205

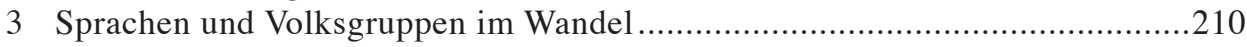

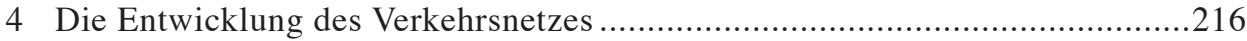

5 Grenzöffnung und grenzüberschreitende Kooperationen...............................220

6 Fazit und Ausblick: Grenzen als Herausforderung .......................................223

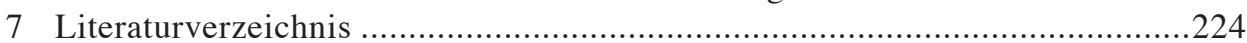

\section{Summary}

Shift of International Borders and its Consequences in the Slovenian-Italian Border Region

This paper focuses on the effects of shifting borders and territories on society and economy investigated by the example of both sides of the Slovenian-Italian border region. After a presentation of the historical background with special regard to shifting territories in the $20^{\text {th }}$ century, the aspect of ethnicity and the status of ethnic minorities are discussed and their spatio-temporal development is documented. Another chapter deals with the development of transportation systems and their interaction with regional economy and population. Finally, examples of cross-border cooperation are shown with a closer look at Gorizia and Nova Gorica, resp., resulting in the statement that the opening of the border in recent times has not resulted in an intensification of transnational cooperation. Yet this would allow the region to derive more benefits from its excellent position in European traffic networks.

* ao. Univ.-Prof. Dr. Peter ČEDE, ao. Univ.-Prof. Mag. Dr. Gerhard Karl LiEB, beide Institut für Geographie und Raumforschung, Karl-Franzens-Universität Graz, Heinrichstraße 36, A-8010 Graz; E-mail: peter. cede@uni-graz.at, gerhard.lieb@uni-graz.at; http://www.kfunigraz.ac.at/geowww/; Mag. Dieter FLECK, Am Bründlbach 10, A-8054 Graz; E-mail: fleck@ regionalentwicklung.at 


\section{Zusammenfassung}

Die Arbeit fokussiert auf die Wirkungen wechselnder Grenzen und staatlicher Zugehörigkeit auf Gesellschaft und Wirtschaft, untersucht am Beispiel des slowenischitalienischen Grenzraumes. Nach einer Darstellung des historischen Hintergrundes mit besonderer Berücksichtigung territorialer Veränderungen im 20. Jh. werden ethnische Fragen und der Status ethnischer Minderheiten diskutiert sowie ihre raum-zeitliche Entwicklung dokumentiert. Ein weiteres Kapitel befasst sich mit der Entwicklung der Transportsysteme und deren Bezug zur Regionalwirtschaft und Bevölkerung. Schließlich werden Beispiele grenzüberschreitender Kooperationen unter besonderer Beachtung von Görz [Gorizia] und Nova Gorica aufgezeigt.Daraus wird die Aussage abgeleitet, dass die jüngste Öffnung der Grenze keine Intensivierung der transnationalen Zusammenarbeit gebracht hat. Die Region könnte dadurch jedoch ihre ausgezeichnete europäische Verkehrslage besser in Wert setzen.

\section{Problemstellung: Grenzen als Barrieren}

Die Erforschung von Grenzen und Grenzräumen hat in der Geographie eine lange Tradition (ANTE 1981, S. 104-125) und ist in Europa besonders seit der politischen „Wende“ von 1989 intensiviert worden (LANGER 2001). Der Fall des „Eisernen Vorhangs" führte nicht zur Abschaffung von Staatsgrenzen, sondern nur zu deren „Defunktionalisierung“ (FrIDRICH 2003, S. 97), die auch mit einer Umbewertung der beiderseitigen Grenzgebiete einherging. Hierbei nimmt die verbesserte Möglichkeit grenzüberschreitend zu kooperieren eine zentrale Rolle ein. Die vorliegende Arbeit greift diese Problematik am Beispiel des slowenisch-italienischen Grenzraumes auf, der durch drei Faktoren besonders hervortritt:

- Obwohl die Grenze Jugoslawiens zu Italien zumindest seit Anfang der 1960er Jahre nicht als Teilstück des „Eisernen Vorhangs“ angesehen werden sollte, war sie doch Trennlinie zwischen dem „östlichen“ und dem ,westlichen“ Gesellschafts-, Politikund Wirtschaftssystem. Trotz ihrer relativen Offenheit auch in der Zeit des Kalten Krieges bildete sich hier - ähnlich wie an den Grenzen zu anderen Reformstaaten - eine deutliche „Wohlstandskante“ aus.

- Die im slowenisch-italienischen Grenzraum lebenden Menschen wurden - abgesehen von den tragischen Ereignissen zweier Weltkriege - im Laufe des 20. Jhs. nicht nur mit mehrfachen Grenzänderungen (heutiger Grenzverlauf erst 1975 endgültig fixiert, vgl. Kap. 2) konfrontiert, sondern hatten sich zudem unter dem Einfluss von vier verschiedenen Staaten (Österreich-Ungarn, Italien, Jugoslawien, Slowenien) mit unterschiedlichen politischen Systemen (Monarchien, faschistischen und kommunistischen Diktaturen, Demokratien) zu arrangieren.

- Aufgrund dieser Sonderstellung ist der gegenständliche Grenzraum bereits mehrfach untersucht worden, wobei vor allem die Arbeiten von Bufon (z.B. 1993, 1996, 2003, jeweils mit weiterführender Literatur) hervorzuheben sind. Dabei hat die italienischslowenische Grenze auch zur Weiterentwicklung theoretischer Konzepte (,,border landscapes“) beigetragen (KLEMENČIČ \& BUFON 1991). 
Als Begründung für eine Neubearbeitung sind die beiden folgenden Aspekte maßgeblich: Erstens sollen soziale Veränderungen in einem stark historischen Zugang durch die kontrastierende Gegenüberstellung der Gegebenheiten zu Beginn des 20. und des 21. Jhs. untersucht werden. Zweitens liegt der Schwerpunkt auf dem jüngsten Wandel und der Frage, ob sich an einer traditionell vergleichsweise offenen Grenze nach dem Inkrafttreten des Schengen-Abkommens (in Slowenien am 21.12.2007) grenzüberschreitende Kooperationen intensiviert haben. Vor diesem Hintergrund fokussieren wir beispielhaft auf die Bereiche Ethnizität (vgl. Kap. 3) und Verkehr (vgl. Kap. 4), weil diese die im angesprochenen Zeitraum eingetretenen Veränderungen besonders deutlich widerspiegeln. Ähnlich wie bei einer früheren Studie über Istrien [Istra $]^{1)}$ (ČEDE et al. 2007) erscheint dieser Zeitraum auch deshalb nicht uninteressant, als bei der Fertigstellung des Manuskripts genau hundert Jahre seit der letzten für den Untersuchungsraum einheitlichen Volkszählung (1910) vergangen waren.

Auf eine strenge räumliche Abgrenzung des Arbeitsgebietes wird bewusst verzichtet (vgl. Kap. 2), der spezielle Fokus liegt jedoch - wie in den Abbildungen 4 und 6 gezeigt - auf den italienischen Provinzen Görz [Provincia di Gorizia] und Triest [Provincia di Trieste] (Teile der Autonomen Region Friaul-Julisch-Venetien [Regione Autonoma Friuli-Venezia Giulia]) und den slowenischen Statistischen Regionen [statistična regija] Goriška regija und Obalno-kraška regija, die sich in etwa mit den historischen Territorien der Grafschaft Görz [Gorizia] und Gradisca [Gradisca d'Isonzo] sowie der Stadt Triest [Trieste] des (österreichischen) Küstenlandes decken. Die Staatsgrenze selbst verläuft in weit geschwungenen Bögen über die Julischen Hoch- und Voralpen [ital. Alpi Giulie, slow. Julijske Alpe], ist im nördlichen Abschnitt seit dem frühen 16. Jh. (Österreichisch-Venezianischer Krieg) unverändert und somit eine der älteren in Mitteleuropa. Etwa ab dem Nahbereich von Görz ist im Gegensatz dazu die Grenze eine der jüngsten Europas und kommt in ihrem längsten Abschnitt auf dem nur dünn besiedelten Plateau des „klassischen“ Karstes [ital. Carso, slow. Kras] zu liegen. Der nördlichste Teil der Grenze bleibt in dieser Arbeit außer Betracht, weil darin stärker trilaterale Beziehungen zwischen Italien, Slowenien und Österreich wirksam sind (BuFON 2003, S. 192-193).

Unsere Arbeit versteht sich weniger als konzeptioneller Beitrag zur Grenz- und Grenzraumforschung, sondern mehr als idiographische Studie. Daraus folgt, dass unser primäres Interesse nicht den Grenzen als solchen gilt (wenngleich wir deren Dimensionen im Sinne von LANGer 2001 wie z.B. Alter, Verlauf, Semantik und Offenheit durchaus berücksichtigen), sondern dem weiteren Grenzraum. Die zentralen Forschungsfragen werden wie folgt formuliert:

- Wie haben sich die beinahe ständigen territorialen Veränderungen des 20. Jhs. auf Ethnizität und Verkehr des heutigen slowenisch-italienischen Grenzraumes ausgewirkt?

\footnotetext{
1) Wenn es für ein geographisches Objekt einen gebräuchlichen deutschen Namen gibt, so wird dieser verwendet. Bei seiner erstmaligen Nennung erscheint zusätzlich in eckigen Klammern der Name in der heutigen Landessprache, in Fällen von amtlicher Mehrnamigkeit erscheinen alle amtlichen Namen. Diese entfallen bei wiederholter Nennung. Ist für ein Objekt kein deutscher Name gebräuchlich, so wird (werden) allein der (die) örtlich gebrauchte(n) Name(n) genannt. In historischen Zusammenhängen werden die zur jeweiligen Zeit gebräuchlichen deutschen oder italienischen Namen verwendet, bei ihrer erstmaligen Erwähnung mit den heutigen ortsüblichen Namen in eckigen Klammern.
} 
- Wie überlagern sich durch die unterschiedlichen Territorialbezüge induzierte sozioökonomische Veränderungen mit anderen raumrelevanten Prozessen?

- Wie steht es um die Rahmenbedingungen von, die Bereitschaft zu und die Realisierung von konkreten Projekten grenzüberschreitender Kooperationen nach der „Defunktionalisierung“ der gegenständlichen Staatsgrenze zu einer EU- und Schengenraum-Binnengrenze?

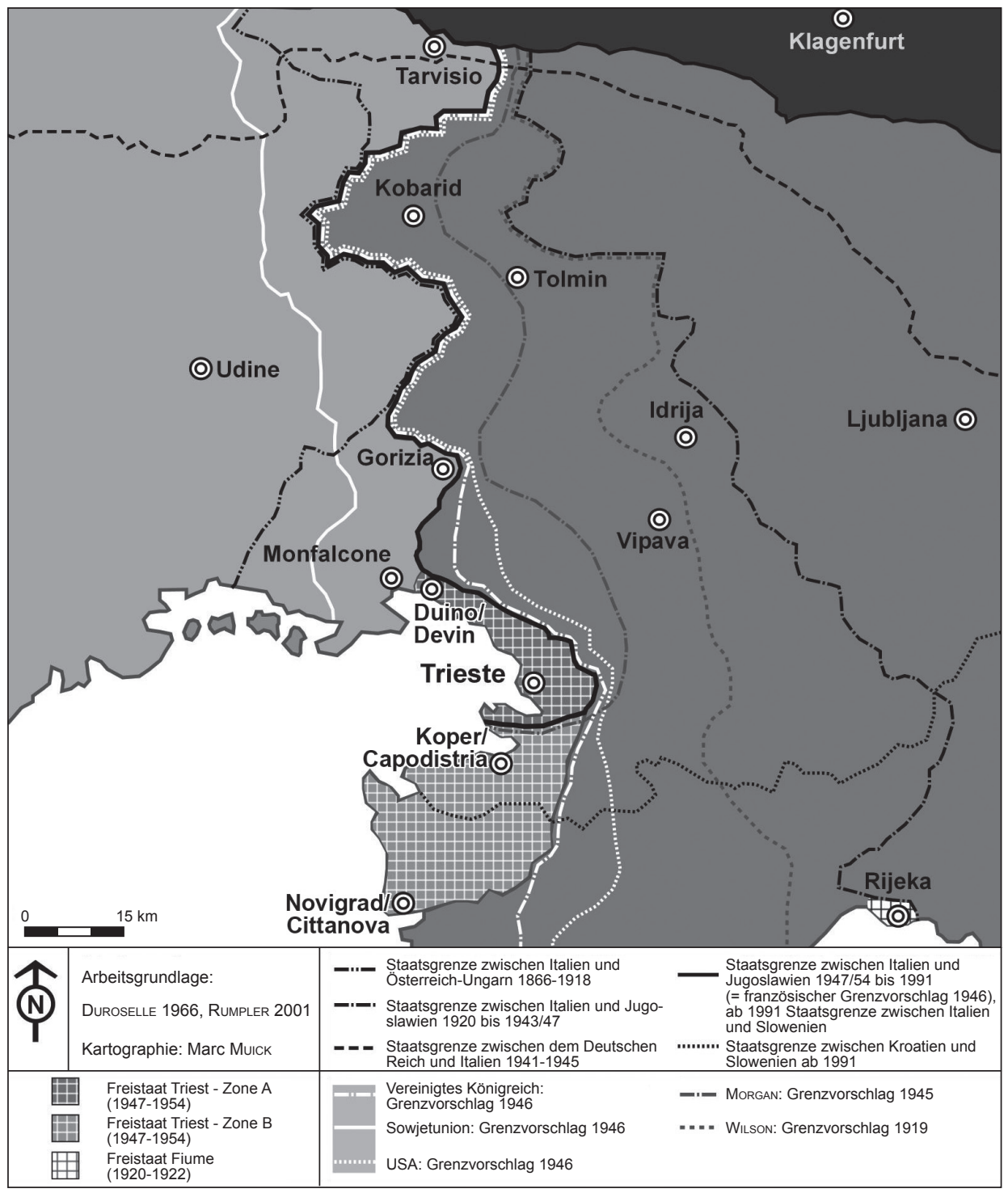

Abb. 1: Der slowenisch-italienische Grenzraum im geopolitischen Kontext des 20. Jhs. 


\section{Die Veränderung von Grenzen und Territorien}

\subsection{Die Folgen des Ersten Weltkrieges}

In der Phase des Zusammenbruchs der Österreichisch-Ungarischen Monarchie okkupierte Italien im November 1918 Görz und Gradisca, Triest und Istrien. Aufgrund des Londoner Memorandums von 1915 betrachtete die Regierung in Rom [Roma] das Gebiet als italienisches Territorium. Mit der Umbenennung des Österreichischen Küstenlan$\mathrm{des}^{2}$ in Julisch-Venetien [Venezia Giulia] (vgl. Kap. 2.4) sollte auch die Namengebung einen Schlussstrich unter die zum Teil Jahrhunderte lange Zugehörigkeit zu Österreich ziehen.

Auf der Pariser Friedenskonferenz 1919/20 ließ sich keine Einigung zwischen Italien und dem neu entstandenen Königreich der Serben, Kroaten und Slowenen [Kraljevina Srba, Hrvata i Slovenaca] hinsichtlich der stark divergierenden territorialen Ansprüche erzielen. Schwierigkeiten ergaben sich bereits daraus, dass zwei Siegermächte miteinander verhandelten. Die südslawischen Vertreter schlugen in der Überzeugung, die slowenische und kroatische Bevölkerung des ehemaligen Österreichischen Küstenlandes würde mehrheitlich für das spätere Jugoslawien votieren, eine Volksabstimmung für Julisch-Venetien vor. Entschieden gegen ein derartiges Plebiszit sprach sich die italienische Regierung aus, die nach wie vor auf der Erfüllung des Londoner Memorandums beharrte, das Görz und Gradisca, Triest und Istrien Italien zugesichert hatte. Die von US-Präsident WILSON vorgeschlagene Teilung des Küstenlandes (Wilsonlinie, vgl. Abb. 1) wurde von beiden Seiten abgelehnt (PIRJEvec 2001, S. 433-435).

Die Pariser Friedenskonferenz überließ die Grenzziehung zwischen beiden Staaten bilateralen Verhandlungen. Am 12.11.1920 wurde der Vertrag von Rapallo unterzeichnet, durch den Italien neben Görz und Gradisca, Triest und Istrien (mit den Inseln Cherso [Cres] und Lussin [Lošinj]) einen Teil von Innerkrain [Notranjsko], Zara [Zadar] sowie die süddalmatinischen Inseln Lagosta [Lastovo] und Cazza [Sušac] erhielt. Die neue Staatsgrenze schuf in Julisch-Venetien nationale Minderheiten, die es bisher nicht gegeben hatte, da in der österreichischen Reichshälfte der Österreichisch-Ungarischen Monarchie alle Volksgruppen de jure gleichberechtigt waren (PIRJEVEC 2001, S. 437).

\subsection{Der Zweite Weltkrieg und seine Auswirkungen}

Während des Zweiten Weltkrieges kam es nach der Kapitulation Italiens im September 1943 in Julisch-Venetien zu einem Volksaufstand, nachdem sich der Widerstand mehrerer Partisaneneinheiten bereits 1941 auf das slowenische Siedlungsgebiet der italienischen Provinzen Görz und Triest ausgedehnt hatte. Dadurch konnte die faschistische Herrschaft im überwiegenden Teil Julisch-Venetiens beseitigt werden. Im Anschluss an die italienische Kapitulation erklärte der Slowenische Nationale Befreiungsausschuss [Slovenski narodnoosvobodilni odbor] den Anschluss des slo-

\footnotetext{
2) Manchmal auch Österreichisch-Illyrisches Küstenland genannt.
} 
wenischsprachigen Küstenlandes an Slowenien. Doch besetzte Hitler-Deutschland noch im Herbst 1943 aus strategischen Gründen Julisch-Venetien, das mit der 1941 von Italien annektierten Provincia di Lubiana (Provinz Laibach [Ljubljana]) sowie mit der gleichfalls besetzten italienischen Provinz Udine [Provincia di Udine] zur Operationszone „Adriatisches Küstenland“ (STUHLPFARRER 1996) zusammengefasst wurde. In deren peripheren Bereichen blieben weiterhin Partisanenverbände aktiv, deren Bekämpfung durch die deutsche Besatzung Zugeständnisse an die slowenischsprachige Bevölkerung erforderte, die von italienischer Seite als Bedrohung der „Italianitá“ Julisch-Venetiens abgelehnt wurden (BAHOvEC 2001, S. 460, 464).

Im November 1943 fasste der Antifaschistische Rat der nationalen Befreiung Jugoslawiens [Antifašistično vijeće narodnog oslobođenja Jugoslavije, AVNOJ] in der bosnischen Stadt Jajce den Beschluss über die Angliederung der slowenischsprachigen Teile des Küstenlandes, Triests und Istriens an Jugoslawien. Der Beschluss wurde vom Slowenischen Rat der nationalen Befreiung [Slovenski narodnoosvobodilni svet] in Gottschee [Kočevje] bestätigt, von den Westalliierten, die insbesondere einen Anschluss Triests an Jugoslawien verhindern wollten, jedoch entschieden zurückgewiesen. Im Gegensatz dazu favorisierte die Sowjetunion die territorialen Ansprüche Jugoslawiens auf „Vereinigung des slowenischen ethnischen Territoriums“. In Italien wurde der AVNOJ-Beschluss nur von der Kommunistischen Partei anerkannt, während das Nationale Befreiungskomitee [Comitato di Liberazione Nazionale] in Triest die Wiederherstellung der Rapallo-Grenze forderte (BAHOvec 2001, S. 465).

Der deutschen Wehrmacht nachrückend besetzte die jugoslawische Nationale Befreiungsarmee nach mehrtägigen Kämpfen Anfang Mai 1945 Triest, nachdem in der Stadt zuvor ein Aufstand linksgerichteter slowenischer und italienischer Widerstandskämpfer begonnen hatte. Aufgrund einer in Duino zwischen den USA, dem Vereinigten Königreich und Jugoslawien abgeschlossenen Vereinbarung (,Duino-Abkommen“) mussten sich die Truppen Titos nach 40 Tagen aus Triest hinter die vom angloamerikanischen Armeekommando festgelegte Demarkationslinie („Morganlinie“, vgl. Abb. 1) zurückziehen, wodurch unter alliierter Militärverwaltung die Präsenz Italiens in Triest, entlang des Isonzo von Monfalcone bis zum Predil [ital. Passo del Predil, slow. Predel] sowie an der NW-Küste Istriens gesichert wurde (RUMPLER 2001, S. 561).

Auf der Pariser Friedenskonferenz 1946/47 wurden verschiedene Vorschläge zur Grenzziehung diskutiert (vgl. Abb. 1). Neben dem ethnischen Standpunkt kamen die Rivalitäten zwischen den ehemaligen Alliierten zum Tragen. Der von sowjetischer und jugoslawischer Seite forcierte Grenzvorschlag holte am weitesten nach Westen aus. Er verlief unter Einschluss von Cividale östlich von Udine, und ganz Julisch-Venetien mit Triest und Istrien wäre somit an Jugoslawien gefallen. Demgegenüber sollte nach britischem Standpunkt Italien sowohl Julisch-Venetien mit Triest als auch den westlichen Teil Istriens erhalten. Man einigte sich schließlich auf einen im Friedensvertrag vom 10.2.1947 unterzeichneten Kompromiss: Julisch-Venetien wurde gemäß dem französischen Grenzvorschlag von 1946, der von allen westlichen Vorschlägen den jugoslawischen Forderungen am weitesten entgegenkam und auf dem Prinzip des ethnischen Gleichgewichtes beruhte (ungefähr gleich starke nationale Minderheiten auf beiden Seiten der Staatsgrenze), geteilt. Das obere Tal des Isonzo [Soča] fiel Jugoslawien zu, die Stadt Görz wurde geteilt (vgl. Kap. 5.2), das untere Isonzotal 
blieb bei Italien. Istrien wurde mit Ausnahme des nordwestlichen Teils Jugoslawien zugesprochen (NEĆAK 2001, S. 496-497; RUMPLER 2001, S. 562).

Zudem war die Errichtung des Freien Territoriums Triest [Free Territory of Trieste/ Territorio Libero di Trieste/Svobodno tržaško ozemlje, FTT/TLT/STO] vorgesehen, das einem Gouverneur mit UN-Mandat unterstehen sollte (vgl. Abb. 1; CASTRO 1982, VALDEvit 1986). Das FTT wurde jedoch - überschattet vom zunehmenden West-OstKonflikt - nicht verwirklicht, da sich die USA, das Vereinigte Königreich, Frankreich und die UdSSR ebenso wie Italien und Jugoslawien nicht auf die Besetzung des Gouverneurpostens einigen konnten. Dadurch blieb die militärische Verwaltung der Westalliierten in der Zone A erhalten, die Zone B stand weiterhin unter jugoslawischer Militärverwaltung (NEĆAK 2001, S. 498-499).

Im Herbst 1953 stationierte Italien mit anglo-amerikanischer Unterstützung Panzerverbände an der Zonengrenze, zudem lehnten London und Washington die weitere Verwaltung der Zone A ab - sie sollte Italien übertragen werden. Jugoslawien reagierte darauf mit einer Teilmobilmachung („Triestiner Krise“). Im Dezember 1953 akzeptierte Italien unter britischem und amerikanischem Druck den Vorschlag Jugoslawiens, wonach sich die Truppen beider Konfliktparteien aus dem Nordwesten Istriens zurückziehen sollten. Danach einigten sich die Vertreter Jugoslawiens, des Vereinigten Königreichs und der USA auf zunächst jugoslawisch-alliierte und in der Folge jugoslawisch-italienische Verhandlungen (NEĆAK 2001, S. 499). Das Londoner Memorandum vom 5.10.1954 regelte schließlich die Frage der Grenzziehung: Zone A wurde der italienischen, Zone B inklusive eines kleinen Teils der Zone A der jugoslawischen Zivilverwaltung unterstellt, wodurch ganz Istrien mit Ausnahme der Gemeinden Muggia und San Dorligo della Valle de facto jugoslawisch wurde. Beide Staaten waren mit dieser Lösung unzufrieden, da sie damit realpolitisch ihre Ansprüche auf die jeweils andere Zone aufgegeben hatten und beide Gebiete vorerst nicht den staatlichen Hoheitsgebieten angehörten (AUPRICH 1995, S. 41).

Durch den Pariser Friedensvertrag und das Londoner Memorandum wurde - wie in anderen Teilen Mitteleuropas - auch in Julisch-Venetien und Istrien eine auf Teilung beruhende Grenze gezogen, die als Folge der weltweiten Frontstellung des „Kalten Krieges“ ihren sichtbarsten Ausdruck in quer über den Bahnhofsplatz von Görz (vgl. Kap. 5.2) verlegten Stacheldrahtrollen fand.

\subsection{Die Lösung der Grenzfrage}

Anfang der 1970er Jahre kam es noch einmal zur politischen Krise, nachdem neofaschistische und nationalistische Gruppen sowie Vereinigungen italienischer ExilIstrianer erneut für die Rückholung ,unerlöster italienischer Heimaterde“ Stimmung gemacht hatten. Anlass dafür war 1974 die Aufstellung mit „Sozialistische Föderative Republik Jugoslawien - Sozialistische Republik Slowenien“ beschrifteter Schilder durch Jugoslawien an der ehemaligen Zonengrenze, wodurch nach italienischer Sichtweise die Demarkationslinie von Jugoslawien zur Staatsgrenze erhoben wurde. Die daraufhin in einer diplomatischen Protestnote Italiens offiziell verwendete Bezeichnung ,italienisches Territorium“ für die ehemalige Zone B betrachtete Jugoslawien als Gebiets- 
forderung Italiens auf einen Teil des jugoslawischen Hoheitsgebietes. Entspannung brachte schließlich der am 10.11.1975 zwischen Italien und Jugoslawien unterzeichnete Vertrag von Osimo, durch den beide Staaten die im Londoner Memorandum fixierte Demarkationslinie als Staatsgrenze anerkannten. Obwohl von einem beträchtlichen Teil der italienischen Bevölkerung abgelehnt, bewirkte die endgültige Lösung der strittigen Grenzfrage in der Folge eine Intensivierung der regionalen Zusammenarbeit (vgl. Kap. 5.1; Ara 2001, S. 484; Auprich 1995, S. 53, 64).

Interessant ist auch, dass 1975 - als letzte territoriale Änderungen nach dem Zweiten Weltkrieg - Teile der 1947 von Jugoslawien besetzten Berge Kolovrat bei Tolmein [Tolmin] und Sabotin bei Görz an Italien abgetreten wurden. Entlang der Hänge des zuletzt genannten Berges verläuft seit Anfang der 1980er Jahre eine Straße exterritorial durch italienisches Hoheitsgebiet von Nova Gorica in die Goriška brda. Diese Straße führt Bufon (2003, S. 190) zu Recht als kurioses Beispiel dafür an, wie weit nationale Politik den regionalen Gegebenheiten hinterher hinken kann. Zur Zeit ihrer Errichtung war sie eigentlich nicht mehr notwendig, und noch 2009 stellte sie sich mit massiven Begleitzäunen und Fotografierverbot als eine anachronistisch anmutende Reminiszenz an den „Eisernen Vorhang“ dar.

Nach der Unabhängigkeit Sloweniens 1991 flammte der italienische Nationalismus unter der neofaschistischen Partei „Alleanza Nationale“ wieder auf. Im Gegensatz dazu verweist jedoch das Ergebnis der ersten nach dem Mehrheitswahlrecht in Triest abgehaltenen Kommunalwahlen - unter Betonung einer „Triestinità“ als bewusste Berücksichtigung der historischen, kulturellen und wirtschaftlichen Sonderstellung der Jahrhunderte nach Mitteleuropa orientierten Stadt - auf eine in den 1990er Jahren erstmals auf breiterer Basis begonnene Überwindung der polarisierenden Vergangenheit (ARA 2001, S. 483-484).

\subsection{Veränderte Raumbezüge im Spiegel von Gebietsnamen}

Der mehrfache Wechsel der staatlichen Zugehörigkeit des Untersuchungsgebietes findet seinen Niederschlag in unterschiedlichen Gebietsnamen, deren temporäre Raumbezüge einer Erläuterung bedürfen. Der Name Küstenland bezeichnet allgemein nicht nur einen Landstreifen am Meer, immer wieder werden damit auch konkrete Verwaltungseinheiten oder Regionen benannt. Als Beispiele mögen der russische Primorskiji krai am Pazifik oder der Verwaltungsbezirk Littoral an der Atlantikküste von Kamerun dienen. Auch beim Österreichischen Küstenland, dem ältesten in dieser Arbeit zu besprechenden Gebietsnamen, handelte es sich um den Namen einer konkreten Verwaltungseinheit. Diese bildete bis 1918 die administrative Gemeinschaft der drei Kronländer „Gefürstete Grafschaft Görz und Gradisca“, „Markgrafschaft Istrien“ und „Reichsunmittelbare Stadt Triest mit ihrem Gebiete“ (Gesamtfläche 7.969 km²), die Selbstverwaltung aufwiesen, jedoch gemeinsam dem kaiserlichen Statthalter in Triest unterstanden.

Zuvor wurden mit den Termini Österreichisches Küstenland, Küstenland oder Litorale Austriaco (ab dem 19. Jh. auch Österreichisch-Illyrisches Küstenland) alle 
innerösterreichischen und in weiterer Folge österreichischen Besitzungen, die an der Adria lagen, zusammengefasst. Die einzelnen Städte und Landstriche wurden zu unterschiedlichen Zeiten habsburgisch, z.B. Triest bereits 1382, der Westen und Süden Istriens schließlich 1797 bzw. 1815. Durch Verwaltungsreformen 1748/49 und 1752 entstand erstmals eine als Litorale Austriaco bezeichnete politische Verwaltungseinheit, die der Intendanz, einer 1731 eingesetzten Wirtschaftsbehörde (ab 1739 in Triest situiert) unterstand. Diese umfasste in der zweiten Hälfte des 18. Jhs. die Gebiete um Aquileia, Triest, Fiume [Rijeka], Buccari [Bakar] und dessen Hinterland bis westlich Karlstadt [Karlovac] sowie die kroatischen Häfen Zengg [Senj] und Karlobag (FABERNeubauer 1993, S. 21-45; Faber 1995, S. 9-11, 265).

Der Name Österreichisches Küstenland ist nur im Kontext des gesamten Staatsgebietes Österreich-Ungarns zu verstehen. Er verbirgt die Tatsache, dass dieses Gebiet nicht nur küstennahe Räume wie die Halbinsel Istrien im Süden oder den östlichsten Teil des Venezianischen Tieflandes [Pianura Veneta], sondern auch ausgesprochen binnenländisch geprägte Landschaften wie die Hochfläche des Karstes oder das Flyschhügelland des Wippachtals [Vipavska dolina] umfasste und im Einzugsgebiet des oberen Isonzo bis hinauf zum höchsten Gipfel der Julischen Alpen (Triglav, $2.864 \mathrm{~m}$ ) reichte.

Primorje oder Primorska sind noch heute gängige Bezeichnungen für jene Gebiete im Westen Sloweniens, die bis 1918 Teil des Österreichischen Küstenlandes waren (slow. primorje $=$ Küstenland). Die Primorska umfasst als moderner vom offiziellen Slowenien verwendeter Kulturlandschafsbegriff (z.B. Republik Slowenien 2009, S. 109-112) im Wesentlichen die beiden slowenischen Statistischen Regionen Goriška regija und Obalno-kraška regija, die im Rahmen der europäischen Systematik der Gebietseinheiten für die Statistik der NUTS-III-Ebene entsprechen (STATISTIČNI URAD Republike SloveniJe 2009). Zuletzt sei noch das für diese Arbeit nicht relevante Kroatische Küstenland [Hrvatsko primorje] (auch Ungarisches Küstenland) erwähnt, das im 18. Jh. eng mit dem Österreichischen Küstenland verwoben war und den Küstenstreifen zwischen der Bucht von Bakar und Karlobag bezeichnete. Der Begriff lebt im Namen der kroatischen Gespanschaft [županja] Primorsko-goranska županja weiter.

Die Bezeichnung Julisch-Venetien [Venezia Giulia] entstand in der Zeit des italienischen Risorgimento und ist damit eine ähnlich konstruierte Benennung für das Umland von Görz und Triest sowie die Halbinsel Istrien wie Alto Adige für Südtirol. Geprägt wurde der Name vom Görzer Sprachforscher G.I. Ascoli in der Mitte des 19. Jhs. (STRASSER \& W AitZBauer 1999, S. 132-133). Nach dem Ersten Weltkrieg wurde Ascolis Wortkreation territoriale Realität (vgl. Abb. 2). Als Teil Italiens reichte die neue Region Julisch-Venetien damals bis zur Adelsberger Pforte [Postojnska vrata], wodurch ein großer Teil der rein slowenischsprachigen Innerkrain mit Adelsberg [Postojna] italienisch wurde. Während des Zweiten Weltkrieges okkupierte Italien auch die restliche Inner- sowie die Unterkrain [Dolenjsko] und schlug diese Gebiete als Provincia di Lubiana zu Julisch-Venetien. Heute beschränkt sich der Begriff JulischVenetien auf die beiden kleinen Provinzen Görz und Triest, die ein Teil der seit 1963 autonomen Region Friaul-Julisch-Venetien mit der Hauptstadt Triest sind. 

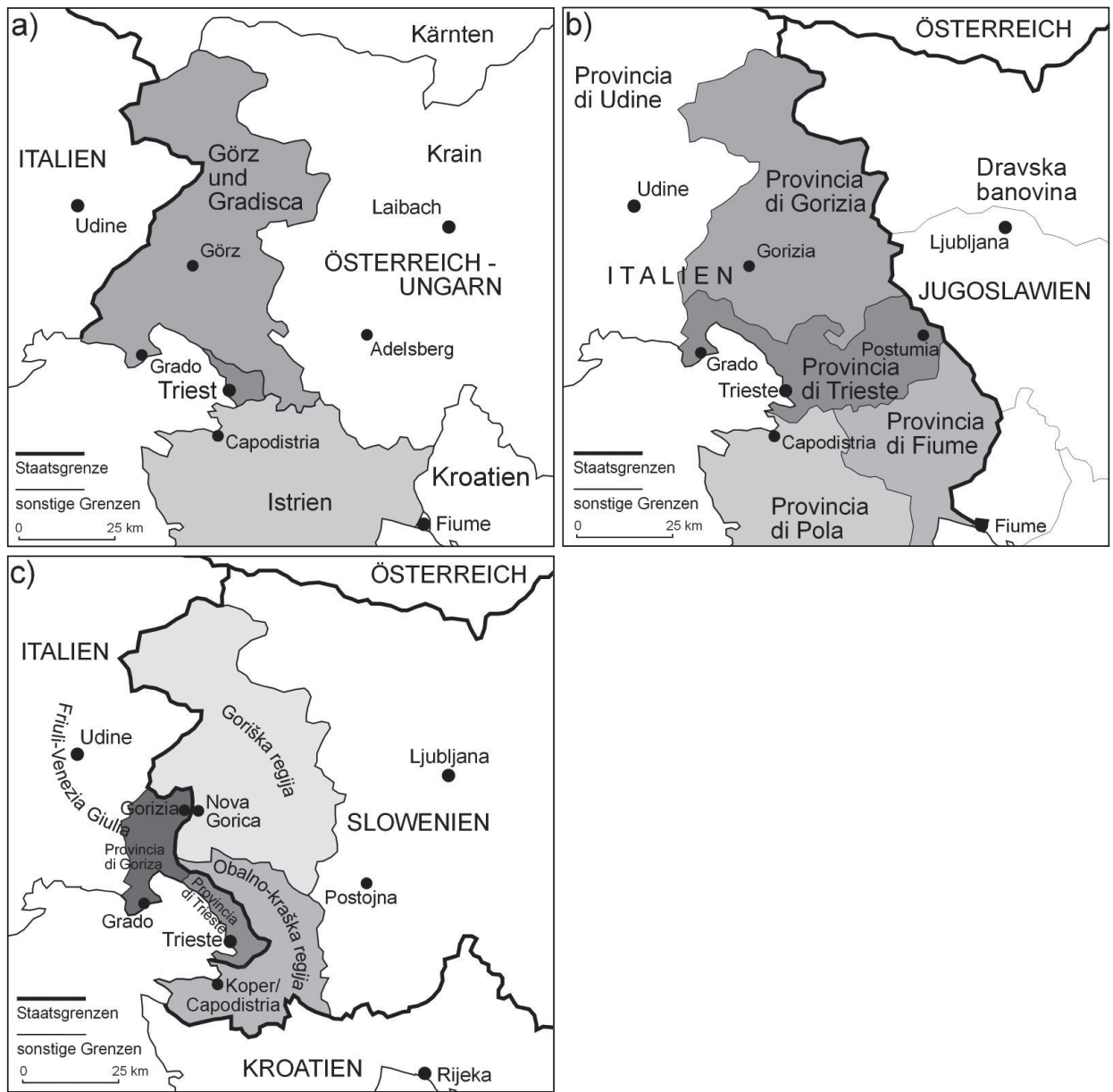

Abb. 2: Die Territorien des Österreichischen Küstenlandes (a) und Julisch-Venetiens (b) im Vergleich mit der aktuellen administrativen Gliederung im slowenischitalienischen Grenzraum (c)

\section{Sprachen und Volksgruppen im Wandel}

\subsection{Die Zeit vor dem Ersten Weltkrieg}

Innerhalb des Österreichischen Küstenlandes war die sprachliche Struktur sehr unterschiedlich. In Görz und Gradisca bildete die slowenischsprachige Bevölkerung, deren autochthones Siedlungsgebiet neben dem Berg- und Hügelland auch den Karst umfasste, mit zwei Dritteln die Mehrheit. Die übrige Bevölkerung war in den urbanen Siedlungen und an der Küste italienischsprachig, während in den ländlichen Siedlungen der Ebene friulanisch gesprochen wurde. In den österreichischen Volkszählungen, die ab 
1880 die „Umgangssprache“ der „einheimischen Bevölkerung“ (1880, 1890, 1900) und der „Staatsangehörigen“ (1910) erfassten, wurde allerdings - aus Rücksichtnahme auf den italienischen Nationalismus - nicht zwischen Italienisch und Friulanisch unterschieden. Schätzungen zufolge lag das Verhältnis von italienisch- zu friulanischsprachiger Bevölkerung bei 1:3 (MoRitsch 2001, S. 358). Nicht unerheblich war der Anteil der deutschsprachigen Bevölkerung in der Landeshauptstadt Görz. In den Jahrzehnten vor dem Ersten Weltkrieg änderte sich die sprachliche Struktur kaum, wobei die Zunahme der romanischsprachigen Bevölkerung zwischen den Volkszählungen 1880 und 1910 primär auf Zuwanderungen aus Italien zurückzuführen ist.

In der in der zweiten Hälfte des 19. Jhs. stark aufstrebenden Hafenstadt Triest (einschließlich „Gebiet“) entwickelte sich das Verhältnis zwischen italienisch- und slowenischsprachiger Bevölkerung - insbesondere aufgrund der Zuwanderung aus dem Triestiner Hinterland - zunehmend zu Gunsten der letztgenannten. Mit einem Anteil von ca. 30\% (1910: 56.916 slowenischsprachige Staatsangehörige) war Triest am Vorabend des Ersten Weltkrieges zur größten slowenischsprachigen Stadt geworden. An dritter Stelle stand auch in Triest die deutschsprachige Bevölkerung. Quantitativ ohne Belang, aber sozial und wirtschaftlich einflussreich waren aus der Hafenfunktion resultierend zudem Griechen, Juden, Armenier (Moritsch 2001, S. 361-362, 398) und Serben (Medaković \& MilošEvić 1987).

In Istrien erreichte die italienisch- und serbo-kroatisch-sprachige Bevölkerung mit je $40 \%$ ähnlich hohe Anteile. Ebenso wie in Görz und Gradisca waren die Städte überwiegend italienischsprachig, der Anteil der deutschsprachigen Bevölkerung konzentrierte sich auf den Kriegshafen Pola [Pula] sowie auf den Kurort Abbazia [Opatija] ${ }^{3)}$, zudem gab es in Istrien mit den Tschitschen eine kleine romanische und mit den Uskoken eine slawische Minderheit (Moritsch 2001, S. 358; ČEdE et al. 2007, S. 141). Ebenso wie in Görz und Gradisca änderte sich auch in Istrien - im Gegensatz zu Triest - das Verhältnis zwischen den einzelnen Sprachen von 1880 bis 1910 kaum. Tabelle 1 zeigt die sprachliche Struktur bei der letzten österreichisch-ungarischen Volkszählung (1910).

\begin{tabular}{|l|c|c|c|c|c|c|}
\hline & $\begin{array}{c}\text { Italie- } \\
\text { nisch }\end{array}$ & $\begin{array}{c}\text { Slowe- } \\
\text { nisch }\end{array}$ & $\begin{array}{c}\text { Serbo- } \\
\text { kroatisch }\end{array}$ & Deutsch & Andere & Summe \\
\hline $\begin{array}{l}\text { Görz und } \\
\text { Gradisca }\end{array}$ & $36,1 \%$ & $61,9 \%$ & $0,0 \%$ & $1,8 \%$ & $0,2 \%$ & 249.921 \\
\hline Istrien & $38,1 \%$ & $14,3 \%$ & $43,4 \%$ & $3,4 \%$ & $0,8 \%$ & 387.174 \\
\hline Triest & $62,3 \%$ & $29,8 \%$ & $1,3 \%$ & $6,2 \%$ & $0,4 \%$ & 190.913 \\
\hline Küstenland & $43,1 \%$ & $32,2 \%$ & $20,6 \%$ & $3,6 \%$ & $0,5 \%$ & 828.008 \\
\hline
\end{tabular}

Anmerkung: Die Angaben beziehen sich auf die Umgangssprache der Staatsangehörigen.

Tab. 1: Die sprachliche Struktur des Österreichischen Küstenlandes 1910 (Arbeitsgrundlage: Volkszählungsergebnisse 1910 aus K.k. Statistische Zentralkommission 1918)

\footnotetext{
3) Abbazia gehört allerdings im kulturräumlichen Sinn nicht mehr zu Istrien, sondern zum Kvarner.
} 


\subsection{Die Zwischen- und Nachkriegszeit}

Nach der Zuteilung des Küstenlandes an Italien wurde die nicht-italienische Bevölkerung einem starken Assimilationsdruck ausgesetzt. Ebenso wie in den übrigen Italien zugesprochenen Teilen Österreich-Ungarns versuchten die staatlichen Behörden auch in Julisch-Venetien die ethnische Struktur unter Betonung der „Italianitá“ massiv zu Gunsten der italienischsprachigen Bevölkerung zu verändern. So wurden über 70.000 Familiennamen romanisiert. Mit der Zerstörung des slowenischen Kulturhauses „Narodni dom“ in Triest fand die antislowenische Unterdrückungspolitik noch vor Abschluss des Vertrages von Rapallo einen vorläufigen Höhepunkt (PIRJEvec 2001, S. 437; Rumpler 2001, S. 559).

Da Italien auf der Friedenskonferenz in Paris 1919/20 zu den Siegermächten gehörte, war der Regierung in Rom kein Minderheitenschutz abverlangt worden. Mit der Machtergreifung der Faschisten 1923 wurden ethnische Säuberungen, die auf eine möglichst rasche Eliminierung der nicht-italienischsprachigen Bevölkerung ausgerichtet waren, Bestandteil der staatlichen Politik. Folge davon war die Entstehung der slowenischen Geheimorganisation TIGR (für Trst, Istra, Gorica, Reka ${ }^{4)}$ ), die als erste antifaschistische Bewegung Europas den Untergrundkampf gegen das Mussolini-Regime aufnahm. Nach einem Schauprozess und der Exekution führender Widerstandskämpfer in Triest 1930 verlor der Kampf der slowenischsprachigen Bevölkerung Julisch-Venetiens vorübergehend an Intensität. Ebenso wie in Istrien, wo während der italienischen Herrschaft ca. 30.000 Kroaten und Slowenen die Halbinsel verlassen hatten, war auch die Anzahl der aus den Provinzen Görz und Triest während der faschistischen Herrschaft nach Jugoslawien emigrierten slowenischsprachigen Bevölkerung nicht unerheblich (Bratulić 1993, S. 44; PirJevec 2001, S. 443-444).

Nach Ausbruch des Zweiten Weltkrieges wurden die Repressalien Italiens in JulischVenetien insbesondere nach der Hinrichtung weiterer TIGR-Widerstandskämpfer in Triest erneut verschärft. Zur Unterbindung von Kontakten zwischen der slowenischsprachigen Bevölkerung und antifaschistischen Untergrundgruppen hatte die Rapallo-Grenze - seit 1941 Binnengrenze zwischen Julisch-Venetien und der durch die Aufteilung der slowenischen Gebiete an Italien gefallenen Provincia di Lubiana - als streng bewachte Polizei- und Zollgrenze weiter Bestand. Der Kampf gegen Faschismus und Nationalsozialismus (seit 1943) intensivierte vorerst das Zusammenwirken italienischer Partisanen mit der jugoslawischen Volksarmee, unvereinbare Positionen über die staatliche Zugehörigkeit der ethnisch gemischtsprachigen Gebiete JulischVenetiens beendeten jedoch eine weitere Kooperation noch vor Kriegsende (BAHOVEC 2001, S. 457-465).

Durch die Angliederung des überwiegenden Teils Julisch-Venetiens an Jugoslawien nach dem Zweiten Weltkrieg und dem dadurch erfolgten neuerlichen Wechsel der staatlichen Zugehörigkeit kam es zu einer markanten Umkehr der Wanderungsströme. Die Auswanderung der italienischsprachigen Bevölkerung aus den Jugoslawien zugesprochenen Gebieten hatte bereits während des Krieges begonnen. Es war keine geplante ethnische Säuberung, die mit dem Zusammenbruch des faschistischen

\footnotetext{
4) Slowenisch für Triest, Istrien, Görz, Rijeka.
} 
Regimes einsetzte, sondern eine Reaktion auf die staatliche Repression, wobei allerdings oft „Italiener“ und „Faschist“" gleichgesetzt wurde. Im Zuge der jugoslawischen Machtübernahme im Frühjahr 1945 ging es der Partisanenführung aber auch um die Abrechnung mit Andersdenkenden, die das kommunistische Regime oder den Anschluss der Belgrad zugesprochenen Teile Julisch-Venetiens an Jugoslawien ablehnten (BAHOVEC 2001, S. 467-468).

Im Gegensatz zu Istrien, wo bis zum Vertrag von Osimo 1975 zwischen 170.000 (LAUŠIĆ 1987, S. 369) und 200.000 Personen (NEJAŠMIĆ 1995, S. 102) vorwiegend italienischer Sprachzugehörigkeit die Halbinsel verlassen hatten, war die Auswanderung italienischsprachiger Bevölkerung aus den Jugoslawien angegliederten Teilen JulischVenetiens ungleich geringer, da vor allem in den alpinen Gemeinden des Isonzotales überwiegend Slowenisch gesprochen wurde. In den Volkszählungsergebnissen spiegelt sich der Exodus der italienischsprachigen Bevölkerung nur unzureichend wider, da bei den Volkszählungen in Jugoslawien nicht nach der „Umgangssprache“, sondern nach der „Nationalität“ gefragt wurde.

\subsection{Jüngere Entwicklungen und aktuelle Situation}

Aufgrund des Londoner Memorandums verfügt die slowenische Bevölkerung in der Provinz Triest seit 1954 über Minderheitenrechte, in der Provinz Görz durch eine entsprechende Interpretation des Autonomiestatus der Region Friaul-Julisch-Venetien seit den 1960er Jahren (Steinicke 1991, S. 34). Erst mit dem Vertrag von Osimo 1975 wurde ein Abkommen zum Schutz der ethnischen Minderheiten beiderseits der Staatsgrenze geschlossen. Nicht zufriedenstellend gelöst ist bisher der innerstaatliche Schutz der slowenischen Minderheit in Italien, die in den Provinzen Görz, Triest und Udine jeweils unterschiedlichen Status aufweist. Seit 1975 ist die italienische Minderheit sowohl im slowenischen als auch im kroatischen Teil Istriens als autochthone Volksgruppe mit vollwertigem Minderheitenschutz anerkannt (vgl. Abb. 3; NEĆAK 2001, S. 511).

In den letzten Jahrzehnten bekannte sich die italienische Minderheit auch in den slowenischen Gemeinden Istriens vermehrt zur italienischen Volksgruppe, wenngleich deren Anteil mit 2,3\% (2002: 1.840 Personen - Statistični uRad Republike SloveniJe, Volkszählung 2002) deutlich unter jenem der kroatischen Gespanschaft Istrien [Istarska županja] (2001: 6,9\% oder 14.284 Personen - DRŽAVNi ZAVOD ZA STATISTIKU, Volkszählung 2001) liegt. Ein zur Volksgruppenzugehörigkeit unterschiedliches Bild zeigt das Bekenntnis zur italienischen Muttersprache, das in den slowenischen Gemeinden Istriens mit 5,1\% (2002: 2.853 Personen - Statistični urad Republike Slovenije, Volkszählung 2002) höher ist als der Anteil der Volksgruppe.

Im Gegensatz zur italienischen Minderheit in Slowenien oder Ex-Jugoslawien wurde die slowenische Minderheit in Italien seit dem Zweiten Weltkrieg im Rahmen offizieller Volkszählungen nur 1961 (Provinz Triest) und 1971 (Provinzen Görz und Triest) erfasst. Inoffiziellen Erhebungen zufolge wird in der Provinz Triest gegenwärtig von bis zu 25.000 Personen Slowenisch gesprochen, für die Provinz Görz werden bis zu 15.000 Slowenischsprachige angegeben (PoHL 2005, S. 99). Im Kontext grenz- 

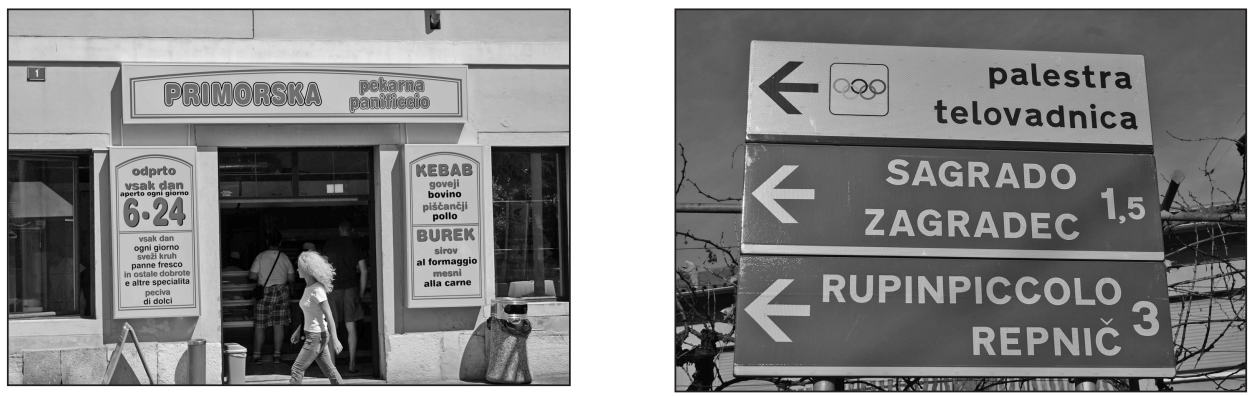

Abb. 3: Zweisprachige Aufschriften als Zeichen gelebten Miteinanders der Volksgruppen beiderseits der slowenisch-italienischen Grenze (links in Koper/Capodistria, Slowenien, rechts in Rupingrande/Repen, Italien) (Foto: LiEb 2009)

überschreitender Beziehungen (vgl. Kap. 5) kommt den Minderheiten beiderseits der Staatsgrenze nach Bufon (2003, S. 188) jedoch eine tragende Rolle zu.

Tabelle 2 zeigt die aktuelle ethnische Struktur im Überblick, Abbildung 4 erlaubt einen genaueren Einblick nach Gemeinden, wobei in beiden Fällen zu beachten ist, dass es sich bei den Angaben für das italienische Staatsgebiet um slowenische Daten ohne Jahresangabe handelt (FRIDL et al. 2001, S. 131).

\begin{tabular}{|l|c|c|c|c|}
\hline & \multicolumn{2}{|c|}{$\begin{array}{c}\text { Wohnbevölkerung mit } \\
\text { italienischer Muttersprache } \\
\mathbf{2 0 0 2}\end{array}$} & \multicolumn{2}{c|}{$\begin{array}{c}\text { Wohnbevölkerung mit } \\
\text { slowenischer Muttersprache } \\
\text { um 2000 }\end{array}$} \\
\hline & absolut & relativ & absolut & relativ \\
\hline Goriška r. & 141 & $0,22 \%$ & & \\
\hline Obalno-kraška r. & 2.888 & $3,07 \%$ & & $11,41 \%$ \\
\hline Gorizia & & & 11.811 & $10,44 \%$ \\
\hline Trieste & & & 25.289 & \\
\hline
\end{tabular}

Tab. 2: Anteil der Wohnbevölkerung mit italienischer Muttersprache in den Statistischen Regionen Goriška regija und Obalno-kraška regija 2002 sowie mit slowenischer Muttersprache in den Provinzen Görz und Triest um 2000 (Arbeitsgrundlage: Volkszählung 2002 aus Statistični uRAd Republike SloveniJe; FRIDL et al. 2001, S. 131)

In jüngster Zeit hat in der Autonomen Region Friaul-Julisch-Venetien das Friulanische - auch als Ausdruck der Ablehnung des römischen Zentralismus - zunehmend an Bedeutung gewonnen. Die Unterschiede zu Rätoromanisch und Ladinisch liegen sowohl in der stärkeren, nicht zuletzt durch die Patriarchen von Aquileia geförderten Latinisierung als auch in keltischen, langobardischen und slawischen Einflüssen. Während die modernen italienischen Volkszählungen die friulanischsprachige Bevölkerung nie erhoben, umfasste diese bei der österreichischen Sprachenzählung 1857 
in Görz und Gradisca 47.841 und bei der ersten italienischen Volkszählung 1921 in der Provincia di Gorizia 50.589 Personen (Steinicke 1991, S. 31). Mit knapp unter $10 \%$ ist der Anteil der friulanischsprachigen Bevölkerung in Julisch-Venetien heute jedoch deutlich geringer als in den Provinzen Udine und Pordenone mit friulanischen Bevölkerungsmehrheiten.

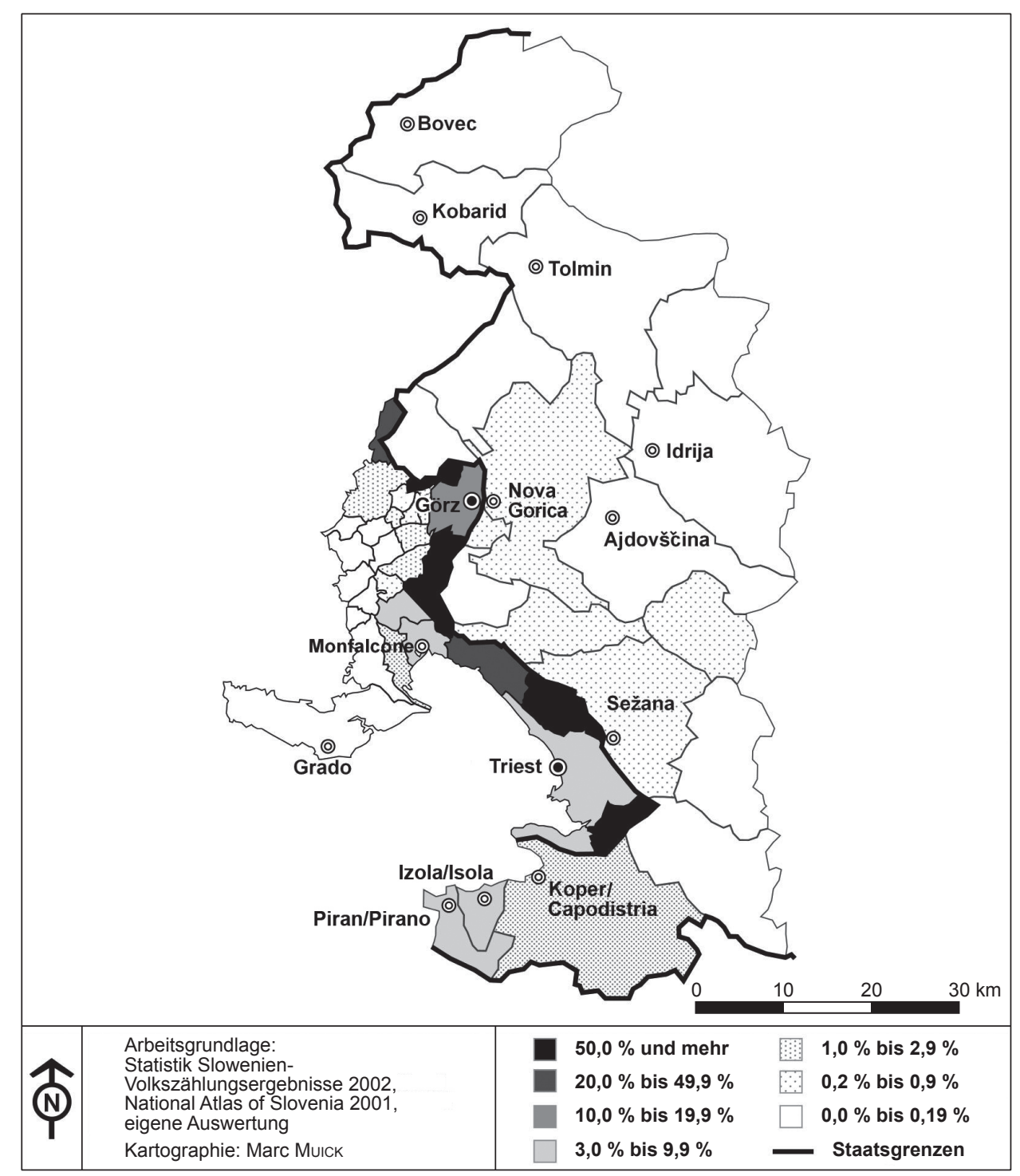

Abb. 4: Anteil der Wohnbevölkerung mit italienischer Muttersprache in den Gemeinden der Statistischen Regionen Goriška regija und Obalno-kraška regija 2002 sowie mit slowenischer Muttersprache in den Gemeinden der Provinzen Görz und Triest um 2000 


\section{Die Entwicklung des Verkehrsnetzes}

\subsection{Topographische, demographische und ökonomische Determinanten}

Die verkehrsgeographische Betrachtung des slowenisch-italienischen Grenzraumes erfolgt einerseits in gezieltem Rekurs auf die in Kapitel 2 dargelegten territorialen Veränderungen, andererseits aufgrund der für die Region prägenden Schlüsselstellung in einem gesamteuropäischen Verkehrssystem, wie sie sich gerade in der jüngsten verkehrspolitischen Diskussion (vgl. Kap.4.3) widerspiegelt. Hierbei ist die Kontinuität der Bedeutung jener topographischen Rahmenbedingungen besonders augenfällig, die aus den spezifischen Reliefverhältnissen am Schnittpunkt des alpinen, dinarischen und mediterranen Naturraumes resultieren. Dabei werden stufenartige Geländestrukturen als Barrieren und Tiefenlinien - insbesondere die Adelsberger Pforte, mit nur $609 \mathrm{~m}$ Scheitelhöhe der niedrigste Übergang über das Dinarische Gebirge [Dinarsko gorje] - als Sammler der Verkehrsströme wirksam (KREBs 1961, S. 277-278).

Eine Schlüsselstellung im Verkehrssystem fällt Triest, dem zentralen Ort der Region, zu. Seit der Erklärung zum Freihafen 1719 hat die Stadt eine außerordentlich dynamische Entwicklung zu einem Hafen von Weltrang im 19. Jh. (Moritsch 2001, S. 363) genommen und war auch am Ende des 20. Jhs. noch der nach dem Umschlag zweitgrößte Hafen Italiens (Rother \& Tichy 2008, S. 312). Diese Stellung hat Triest allerdings - wie PAschinger (1955, S. 241-243) treffend dargelegt hat - nicht wegen, sondern trotz seiner Lage inne: Diese ist in großräumiger Perspektive wegen der das weitere Hinterland seit dem Ende des Ersten Weltkrieges durchschneidenden Grenzen und kleinräumig wegen der im Maximum bis zu 400 m hohen Geländestufe (,Karstrandstufe“, vgl. Abb. 5) am unmittelbaren Stadtrand als doppelt ungünstig zu bewerten.

Deshalb war die Stadt in ihrer Geschichte stets auf Förderungen von außen angewiesen (PASChINGer 1955, S. 243), im 20. Jh. etwa durch die Anlage des Ölhafens als Ausgangspunkt der transalpinen Ölpipelines nach Bayern und Österreich 1967 (Rother \& Tichy 2008, S. 199). Parallel dazu musste aus Platzmangel die Werftindustrie nach Monfalcone an den Rand des Venezianischen Tieflands mit ausreichenden Flächenreserven verlegt werden. Sie war dort der dynamischen Bevölkerungs- (vgl. Abb. 6), Siedlungs- und Wirtschaftsentwicklung sehr förderlich. Unterdessen gelang es dem slowenischen Nachbarhafen Koper/Capodistria, sich im lukrativen ContainerFrachtverkehr als starker Konkurrent Triests zu etablieren (vgl. Kap. 4.3). Von den im Hinterland der Küste liegenden Städten kommt mit Ausnahme von Görz (vgl. Kap. 5.2) keine in ihrer wirtschaftlichen Bedeutung an die drei genannten heran.

Aufgrund ausgeprägter räumlicher Disparitäten müssen dem übrigen Untersuchungsgebiet weithin periphere Züge attestiert werden, was vor allem für den gebirgigen Teil der Statistischen Region Goriška regija beiderseits des oberen Isonzo gilt. Diese wird in slowenischen Studien mit Aussagen wie „,demographisch besonders gefährdetes Gebiet“ (z.B. Gosar \& Roblex 2001, S. 144) oder „dying out of population has even become more intense, e.g. the Tolmin region" (RAVBAR \& KLEMENČIČ 1993, S. 150) charakterisiert, auch wenn die Entsiedlung noch nicht so weit fortgeschritten ist wie in der benachbarten Montagna friulana (ČEDE \& STEINICKe 2007). Dies bringt auch Abbildung 6 zum Ausdruck, die für den gesamten Nordteil des untersuchten Gebietes rückläufige Bevölkerungszahlen ausweist. 


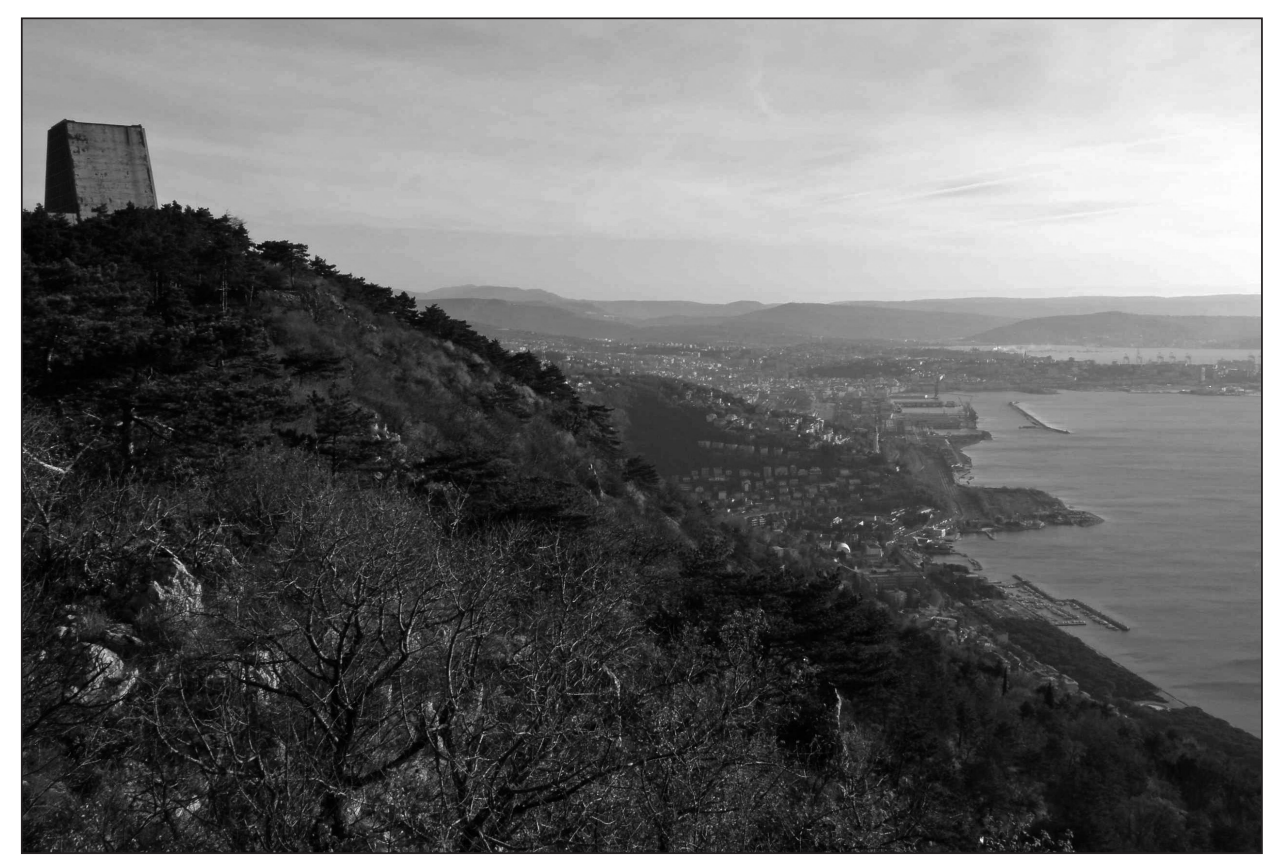

Abb. 5: Blick vom oberen Rand der Karstrandstufe nach Süden auf Triest, links im Bild das Santuario Mariano Monte Grisa (Foto: Lieb 2009)

Ein weiterer Ungunstraum ist das Plateau des „klassischen“ Karstes, insbesondere auf slowenischem Staatsgebiet. Der dort starke Bevölkerungsrückgang ist als Landflucht in Folge der Litoralisierung in den slowenischen Küstengemeinden (ausführlicher hierzu ČEDE et al. 2007) zu deuten, die Bevölkerungszunahme in den italienischen Gemeinden dieses Gebietes hingegen als Suburbanisierung. Diese Prozesse sind somit primär den zuvor genannten Faktoren und nur sekundär den in Kapitel 2 dargestellten Grenzveränderungen zuzuschreiben.

\subsection{Der historische Kontext}

Zu Beginn des 20. Jhs. war das Österreichische Küstenland mit dem Zentralraum der Monarchie um Wien durch die 1857 auf der gesamten Länge fertig gestellte Südbahn (Dultinger 1985) verbunden. Entgegen deren traditioneller Deutung als Transportachse für Handelsgüter ist jüngst verstärkt auf ihre militärstrategische Funktion hingewiesen worden (OBEREGGER 2006). Dies gilt noch mehr für die zweite Alpentransversale, mit der das ,,alte Österreich“ das Küstenland erschloss, die erst 1906 eröffnete Wocheinerbahn (ital. „Transalpina“, slow. „Bohinjska železnica; vgl. Kap. 5.2 und Eicher 2009, S. 69-74). In der zweiten Hälfte des 19. Jhs. waren die Städte Triest und Görz auch durch mehrere Bahnlinien mit ihrem Hinterland und den benachbarten Wirtschaftsräumen verbunden worden (z.B. schon 1860 mit Venedig [Venezia] und 1873 mit Fiume [Rijeka], wodurch dem Hafenstandort Triest auch 
Konkurrenz erwuchs). Dabei war die Überwindung der Karstrandstufe (vgl. Abb. 5) stets das größte technische Problem. Dennoch bestanden am Vorabend des Ersten Weltkrieges drei, durch eine Bahn entlang des Hafens vernetzte Verbindungen vom Karstplateau nach Triest - nämlich die Südbahn von Opicina/Opčine über Aurisina/ Nabrežina, die Bahn von Hrpelje-Kozina durch die Val Rosandra und die Karstbahn von Opicina/Opčine (OBEREGGer 2006).

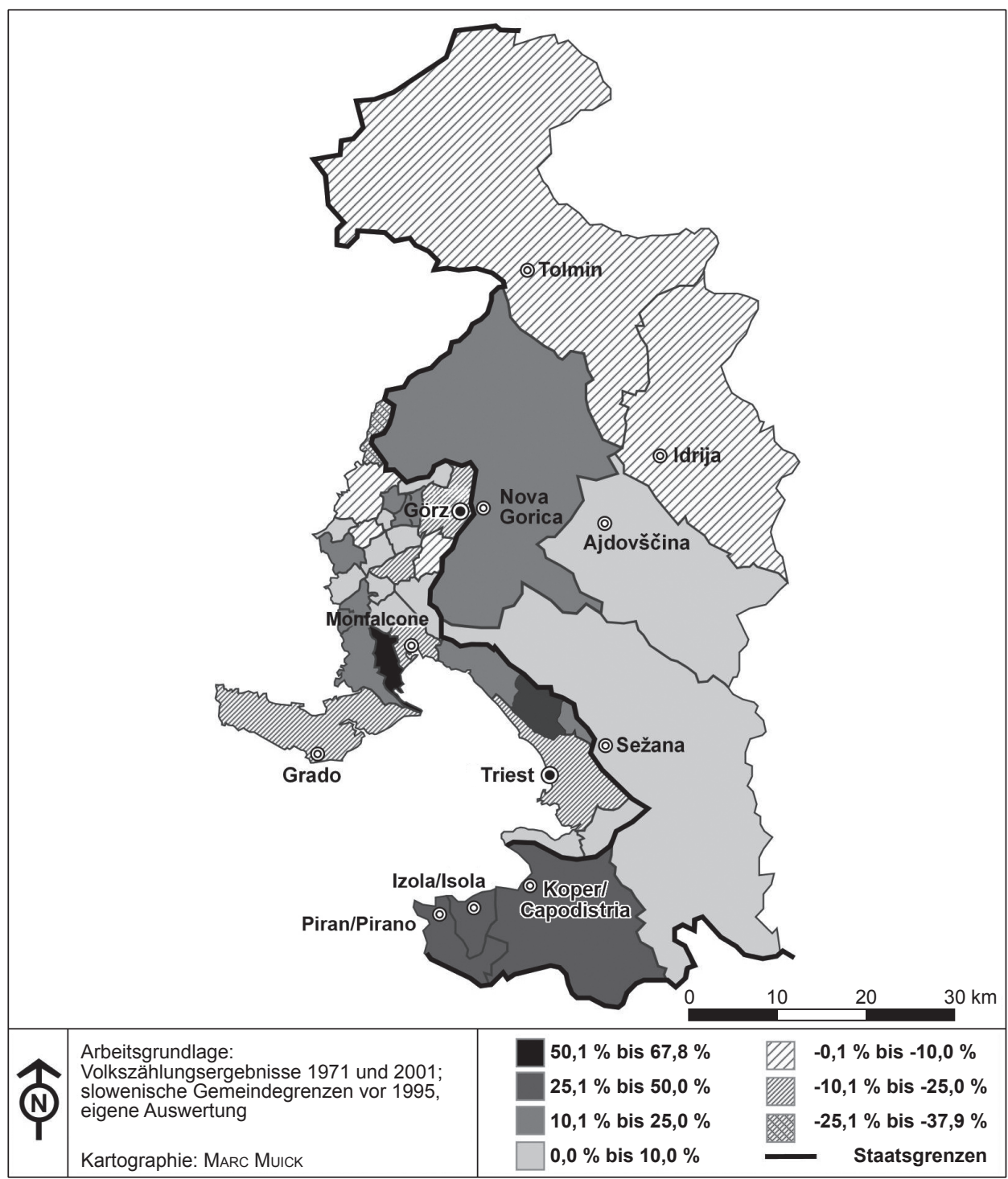

Abb. 6: Bevölkerungsentwicklung in den Gemeinden der Provinzen Görz und Triest sowie in den Gemeinden der Statistischen Regionen Goriška regija und Obalnokraška regija von 1971 bis 2001 
Die nach dem Ersten Weltkrieg neu gezogenen Staatsgrenzen durchschnitten die beiden Hauptverkehrsachsen aus der österreichischen Zeit und verringerten deren Bedeutung stark, was besonders für die Wocheiner Bahn gilt. Das faschistische Italien ventilierte erneut die schon ältere Idee einer Predilbahn - als Verbindung zum nunmehr auch dem italienischen Staatsgebiet angehörigen Kanaltal [Val Canale] -, realisierte diese aber ebenso wenig wie andere Verkehrsprojekte. Auch die während des Ersten Weltkrieges aus strategischen Gründen von Italien errichtete schmalspurige Stichbahn von Cividale nach Karfreit (ital. Caporetto) [Kobarid] wurde 1932 wieder eingestellt (Dante-Alighieri-Gesellschaft Klagenfurt 2008). Drei Jahre später kam es weiters zur Stilllegung der erst 1902 erbauten Schmalspurbahn „Parenzana“, die Triest mit Parenzo [Poreč/Parenzo] (Istrien) verbunden hatte (IstRiaNet 1998).

In der Nachkriegszeit wurden die Rahmenbedingungen noch schwieriger, sowohl wegen der neuen Grenzziehung als auch wegen der langen Unsicherheit um den Status von Triest (vgl. Kap. 2.2). Schon vor der endgültigen Fixierung der Staatsgrenze 1975 legte Jugoslawien zwei durch den Grenzverlauf auf dem Karstplateau gekappte Verbindungen still. Stattdessen wurde mit der Strecke Hrpelje-Sežana (1949) eine innerslowenische Verbindung über den Karst nach Görz errichtet. Zudem wurde Koper/ Capodistria 1967 durch eine neue elektrifizierte Stichbahn erschlossen - als Grundlage für die später so dynamische Entwicklung dieses Hafens. Von einem innerstädtischen Eisenbahntunnel in Triest abgesehen, konzentrierten sich die verkehrspolitischen Anstrengungen Italiens hingegen auf den Straßenbau, wobei es einmal mehr die Karstrandstufe war, die den vollständigen Anschluss der Stadt an das italienische Autobahnnetz bis in jüngste Zeit verzögerte.

\subsection{Der aktuelle Kontext}

Die jüngste Entwicklung zeichnet sich durch zwei wesentliche Faktoren aus. Erstens sind dies die politische „Wende“ und die Unabhängigkeit Sloweniens 1991 sowie dessen Eingliederung in die Europäische Union (EU) (Beitritt 2004, Einführung des Euro und Inkrafttreten des Schengen-Abkommens 2007), zweitens die Vorgaben der gesamteuropäischen Verkehrspolitik. Dies führte dazu, dass sich die Republik Slowenien verstärkt den ,westlichen“ Nachbarstaaten Österreich und Italien zuwandte, aber auch für die ostmitteleuropäischen Reformstaaten zu einem wichtigen Transitland wurde, wobei sich vor allem Koper/Capodistria zum Haupthafen dieser Binnenländer (JuRIČ 1996, S. 38) entwickelte. Daher kam es zu einer massiven (Wieder-)Aufwertung der NE-SW-Verkehrsachse durch Slowenien, die sich in einem außerordentlichen Anstieg des Verkehrsaufkommens äußerte und mit einem dynamischen Ausbau der Straßen einherging (HiLPERT \& KRÄUSSLICH 2007, S. 47).

Seit 2009 führt eine Autobahn durchgehend von der ungarischen bis zur italienischen Staatsgrenze. Im Untersuchungsgebiet verzweigt sich dieser Hauptverkehrsstrang in drei Richtungen (Autobahnen nach Görz, Sežana und Triest, Koper/Capodistria), was die hohe verkehrs- und wirtschaftspolitische Wertschätzung dieses Grenzraumes durch Slowenien (bei gleichzeitiger Vernachlässigung des Grenzraums zu Kroatien) symbolisiert. Zugleich wurde jedoch das Angebot auf der Schiene dramatisch reduziert: So 
beinhaltete der Fahrplan 2010 nur noch ein grenzüberschreitendes Personenzugpaar zwischen Italien und Slowenien (SLovensKe ŽELEZNICE 2010).

Die internationale Verkehrspolitik hat Europa mit dem Konzept von TEN (TransEuropean Networks; LichTENBERGER 2005, S. 294-296) einen Planungsraster für den bevorzugten Ausbau eines Hochleistungs-Verkehrsnetzes gegeben. Der slowenischitalienische Grenzraum wird dabei von der Achse TEN-6 (Lyon - Triest - Laibach [Ljubljana] - Budapest - Ukraine) durchquert, an der vor allem die Schiene ausgebaut werden soll. Bislang investierte Slowenien wenig in den Ausbau dieser Achse, weil es sein Autobahnnetz forcierte. Zudem erweist sich sowohl das Relief des slowenischen Binnenlandes als auch die Überwindung der Karstrandstufe selbst für HochtechnologieVerkehrswege (EICHER 2009, S. 201-202) als problematisch. Von der EU kam deshalb der Vorschlag, kurzfristig eine Bahnverbindung von Triest nach Koper/Capodistria zu errichten, um die beiden Häfen zu vernetzen und mittelfristig den Verkehr von der oberen Adria über die Hochleistungsstrecke der Pontebbana und durch Österreich in die ostmitteleuropäischen Reformstaaten zu lenken (Palacio 2006, S. 12). Diese unbefriedigende Situation des Eisenbahnverkehrs zeugt weniger von mangelndem grenzüberschreitendem Kooperationswillen als vielmehr von einer straßenzentrierten Verkehrspolitik. Unabhängig davon unterstreicht die Führung der TEN-6 durch den Untersuchungsraum dessen bevorzugte Verkehrslage.

\section{Grenzöffnung und grenzüberschreitende Kooperationen}

\subsection{Vom Einkaufstourismus zu INTERREG-Projekten}

Entscheidend für eine Änderung der politischen Rahmenbedingungen nach dem Zweiten Weltkrieg war neben der Lösung der Triestiner Frage auch die Beilegung des „Kominform-Konflikts“ zwischen Jugoslawien und der Sowjetunion, wodurch die Möglichkeiten für Kooperationen zwischen dem blockfreien Jugoslawien und dem Westen und daher auch mit Italien deutlich verbessert wurden. Von einem „Eisernen Vorhang" kann im Untersuchungsgebiet spätestens seit der 1961/62 aus politischen und ökonomischen Gründen erfolgten Öffnung der jugoslawischen Staatsgrenzen nicht mehr gesprochen werden. (Das erste Abkommen über den lokalen Grenzverkehr wurde nach Bufon 2003, S. 182 bereits 1947 geschlossen.) Dadurch konnte insbesondere Triest zwar nicht an seine frühere Bedeutung als zentraler Ort der gesamten Region anknüpfen, durch den Einkaufstourismus aus den jugoslawischen Teilrepubliken Slowenien und Kroatien ergaben sich jedoch positive Impulse für eine Verbesserung der Wirtschaftslage der bis dahin weitgehend isolierten Stadt. Hand in Hand damit etablierte sich, trotz entschiedener Ablehnung durch nationalistische Gruppen in Italien, ein neues Klima des Verständnisses und der Dialogbereitschaft beiderseits der Staatsgrenze (ARA 2001, S. 482; NeĆAK 2001, S. 509-514).

Den Daten von Bufon 1996 zu Folge gab es Anfang der 1990er Jahre bei einer Grenzlänge von $202 \mathrm{~km}$ (17\% der gesamten Grenzlänge Sloweniens) 31 offizielle Grenzübergänge von Slowenien nach Italien (39\% aller Grenzübergänge Sloweniens). 
Demnach ist die Grenze zu Italien die diesbezüglich offenste Sloweniens, weshalb es hier schon seit den 1960er Jahren nicht nur den erwähnten Einkaufs- (stärker von Slowenien nach Italien) und Ausflugsverkehr (stärker in umgekehrter Richtung; Einzelheiten hierzu bei BUFON 2003), sondern auch ein quantitativ nicht unbedeutendes Grenzgängertum gibt: Um das Jahr 2000 pendelten im Untersuchungsgebiet bereits rund 7.000 Personen von Slowenien nach Italien (ZuPANČıč 2002, S. 150).

Grenzüberschreitende Kooperationen im Sinne eines gemeinsamen öffentlichen Auftrittes und der Abwicklung bi- oder multilateraler Projekte begannen im Wesentlichen mit der Gründung der Arbeitsgemeinschaft (ARGE) Alpen-Adria 1978, der als Gründungsmitglieder auch die Autonome Region Friaul-Julisch-Venetien sowie die Sozialistische Republik Slowenien angehörten. (Nach Bufon 2003, S. 180, war dies die erste grenzüberschreitende Kooperation über den „Eisernen Vorhang“ hinweg.) Mit der Annäherung Sloweniens und seinem Beitritt zur EU 2004 kam es zu einer Intensivierung der Zusammenarbeit, wobei zuletzt die meisten Projekte im Rahmen der Förderschiene INTERREG IIIA Slowenien-Italien 2000-2006 (Rener 2004) abgewickelt wurden. Für die laufende Förderperiode 2007-2013 gibt es ein vom Europäischen Fonds für Regionale Entwicklung (EFRE) kofinanziertes operationelles Programm Italien-Slowenien im Rahmen des Ziels „Europäische territoriale Zusammenarbeit“ [Cooperazione territoriale europea 2010].

Eines von zahlreichen Beispielen hierfür ist das Projekt „Sabotin Park Miru“ (2009), das Relikte des Ersten Weltkriegs im Bereich des in dieser Hinsicht besonders symbolträchtigen Berges Sabotin bei Görz im Sinne eines Friedensparks neu inszeniert. Trotz (touristischer) Attraktivität und Professionalität ist dabei jedoch - wie auch für viele andere Projekte - symptomatisch, dass (aufgrund des Leadpartner-Prinzips) zwar die Philosophie, die herausgebrachte Karte (Mestna obČInA Nova Gorica 2006), andere Broschüren und die Wanderwege tatsächlich grenzüberschreitend sind, das Projekt aber letztlich doch ein slowenisches war, das auf der italienischen Seite der Grenze zwar bekannt ist und von dort auch gut besucht, aber nicht beworben wird.

\subsection{Das Fallbeispiel Görz}

Görz wurde durch den Pariser Friedensvertrag 1947 (vgl. Kap. 2.2) geteilt, indem das historische Stadtzentrum mit der Burg der Grafen von Görz und den im Westen liegenden Vorstädten bei Italien verblieb, während die östlichen Vororte Šempeter und Solkan an Jugoslawien fielen. Innerhalb des Stadtgebietes orientierte sich der Grenzverlauf an der Trasse der Wocheinerbahn, die ebenso wie der Bahnhof an Jugoslawien kam. Dadurch war ein Großteil des mehrheitlich slowenischsprachigen Hinterlandes von Görz an Slowenien gefallen, das zugehörige Regionalzentrum jedoch nicht (weitere Details bei Bufon 2003, S. 182). Für das sozialistische Jugoslawien war es somit sowohl eine Frage regionalpolitischer Notwendigkeit als auch identitätsstiftender und systemstärkender Selbstinszenierung, im Anschluss an das Dorf Solkan ab 1948 mit Nova Gorica eine neue, nach sozialistischen Prämissen geplante Stadt aus dem Boden zu stampfen (Gosar \& Jeršř 1999, S. 163). Dass sich diese Stadt in der Folge gut entwickelte (2008: 31.911 Einwohner; StatističNi URAd Republike SloveniJe), hat 
wenig mit grenzüberschreitenden Kooperationen zu tun, sondern erklärt sich leichter aus folgenden Faktoren:

- Slowenien bemühte sich bereits in sozialistischer Zeit um eine Regionalpolitik, deren Leitbild eine ,polyzentrische“ Siedlungs- und Wirtschaftsstruktur war. Die in Bezug auf den slowenischen Zentralraum peripher liegende Stadt konnte sich daher gezielter Förderung sicher sein, die ihr unter anderem 1995 den Status einer Universitätsstadt brachte (DrozG 2008, S. 292).

- Entsprechend der Feststellung bei Jordan (2006, S. 121), dass die westlichen Grenzgebiete der meisten Reformstaaten als regionale „Gewinner“ des Transformationsprozesses hervortreten, wirken sich die schon seit Jahrzehnten offenen Grenzen - zumal in der Nachbarschaft eines wirtschaftlich dynamischen Teilraumes des „Dritten Italien“ (Rother \& Tichy 2008, S. 204-205) - und das Grenzgängertum (vgl. Kap. 5.1) für Nova Gorica besonders günstig aus.

- Vor diesem Horizont ist Nova Gorica auch zu einem attraktiven Zielort für ausländische Investitionen geworden, was in den letzten Jahren unter anderem dazu geführt hat, dass das Stadtzentrum durch Casinos und zugehörige Hotels stark umgestaltet wurde („europäisches Las Vegas“; Keller \& FörSTER 2007, S. 253). Damit ist die Stadt auch zu einem bedeutenden Tourismuszentrum (2008: 117.224 Übernachtungen, Statistični urad Republike Slovenije 2009) mit Haupteinzugsgebiet NordostItalien geworden (BufON 2003, S. 190).

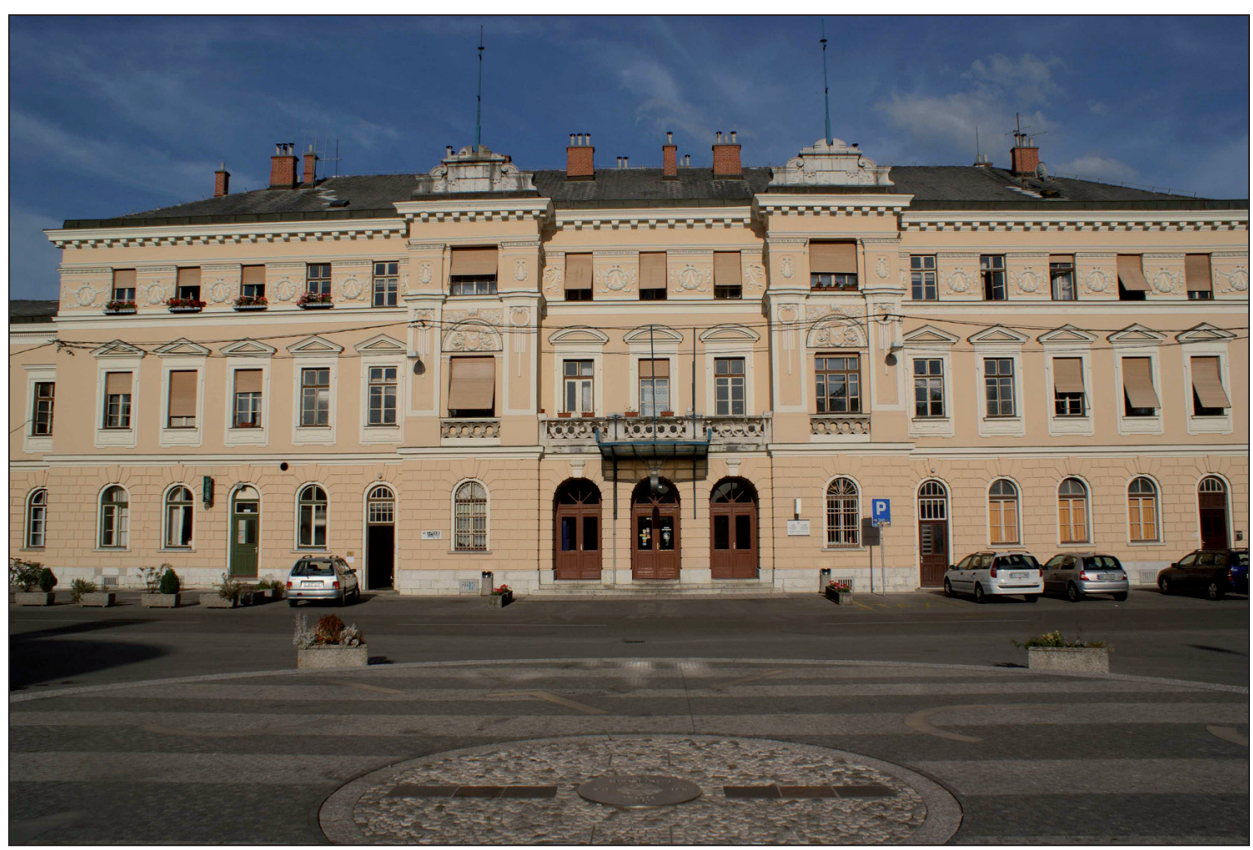

Abb. 7: Der Bahnhof der Wocheinerbahn in Görz, Blick von der italienischen Seite des Bahnhofsvorplatzes (Piazza Transalpina, Trg Evrope) zum auf der slowenischen Seite liegenden Bahnhofsgebäude. Die Linie im Vordergrund markiert die Staatsgrenze, an der bis 2004 ein Zaun verlief (Foto: Lieb 2009). 
Eine vergleichbare Dynamik fehlt der historischen Stadt Görz (2009: 35.966 Einwohner, Istituto nAZIONALE Di STATISTICA) auf der anderen Seite der Staatsgrenze weithin - ein von BRAUN 2009 sehr anschaulich geschilderter Gegensatz, der mit der aus italienischer Perspektive überaus peripheren Lage der Stadt zusammenhängt. Umso mehr könnten grenzüberschreitende Kooperationen ein Gebot der Stunde sein. Doch auch hier fällt auf, dass die Bemühungen bescheiden bleiben. Eine im Rahmen einer Arbeitsexkursion 2009 durchgeführte Internet-Recherche durch Grazer Studierende erbrachte zwar eine große Zahl an Einzelprojekten, aber keine Initiativen, die in gröBerem Stil kommunale Belange (z.B. gibt es nur eine grenzüberschreitende Buslinie) oder wirtschaftliche Kooperationen umfassen würden. So stellt die Mission OPÉRATIONELLE TRANSFRONTALIÈRE (2009) fest, dass die Kooperation vor 1991 intensiver als heute gewesen wäre und etwa beim Tourismus die beiden Städte mehr konkurrieren als kooperieren.

Vielmehr gewinnt man den Eindruck, dass sich nach der Grenzöffnung zwar ein ,unkompliziertes“ Leben in zwei Städten eingestellt hat, sich die Doppelstadt Görz im Übrigen aber mehr als Kulisse spektakulärer Inszenierungen denn als Ort echter grenzüberschreitender Zusammenarbeit präsentiert. Dies sieht man besonders eindrucksvoll an der Piazza Transalpina/Trg Evrope, dem Vorplatz des Bahnhofs der Wocheinerbahn (vgl. Abb. 7): Über ihn verlief bis 2004 ein vielfach (wenn auch unzutreffend) als letzter Rest des „Eisernen Vorhangs“ apostrophierter Zaun, der den Bahnhof von Italien aus (und somit von der Stadt, die er einst erschlossen hatte) unzugänglich machte. Heute ist der Platz als Zeichen eines vereinten Europa durchaus sehenswert inszeniert, es überqueren ihn aber nur wenige Passanten. Die prognostizierte Intensivierung der Beziehungen lässt also, gerade im Sinne der ",reation of a single urban area“ (BuFoN 2003, S. 190), noch auf sich warten.

\section{Fazit und Ausblick: Grenzen als Herausforderung}

Unter Rückgriff auf die eingangs gestellten Forschungsfragen kommt man im slowenisch-italienischen Grenzraum zur Feststellung, dass sich die hier tatsächlich dramatischen territorialen Änderungen (bis 1975!) erwartungsgemäß in vielfacher Hinsicht ausgewirkt haben. Dabei waren vor allem die Entstehung ethnischer Minderheiten beiderseits der neuen Staatsgrenze und die mit den nationalstaatlichen Ansprüchen einhergehenden Migrationsbewegungen von Bedeutung. Hinzu kommt eine insgesamt als Peripherisierung zu bezeichnende Umwertung des Raumes durch die jeweils neuen territorialen Bezüge. Dies kann besonders an der retardierten Entwicklung von Triest und (Alt-)Görz gezeigt werden, während die Dynamik von Nova Gorica erst durch die neuen Grenzen ermöglicht wurde.

Diese durch den wiederholten Wechsel der staatlichen Zugehörigkeit verursachten Prozesse überlagern sich mit anderen raumrelevanten Entwicklungen, von denen in unserer Arbeit einige angesprochen werden konnten. Hierzu gehören etwa Suburbanisierung (am Beispiel der Stadtumlandgemeinden von Triest und Monfalcone) oder Litoralisation (besonders an der slowenischen Küste) sowie Land- und Bergflucht, 
wie sie insbesondere in der Entleerung des Gebirgsraumes der südlichen Julischen Alpen in Erscheinung tritt. Nicht näher untersucht wurden hingegen Prozesse wie die zunehmende Tertiärisierung (sehr deutlich etwa in Nova Gorica, Drozg 2008, S. 290 292) oder der Strukturwandel im Hafen von Triest und dessen seit 2000 schrittweise umgesetzte Kooperation mit seinen nahen Konkurrenten Koper/Capodistria (BuFoN 2003, S. 189) und Rijeka.

Die „Defunktionalisierung“ der gegenständlichen Staatsgrenze zu einer EU- und Schengen-Binnengrenze wurde aufgezeigt und dadurch deutlich gemacht, dass in einem gemeinsamen Europa nunmehr gute Rahmenbedingungen für grenzüberschreitende Kooperationen vorliegen. Die einschlägigen Programme werden auch genützt, vielfach handelt es sich jedoch nur um „kleine“, unspektakuläre Projekte. Die Bereitschaft wirklich vorbehaltlos aufeinander zuzugehen ist - wie in anderen Grenzgebieten zu den Reformstaaten auch - allerdings noch entwicklungsfähig und der Weg zu einer echten „,cross-border-governance“ (die hier aber ohnehin nicht erwartet worden war) somit noch weit. Die Feststellung "The border has thus ceased to be a geographic and strategic dividing line but has become a factor of regional connectivity" (KLEMENČIČ \& BUFON 1991, S. 87) entsprang aus heutiger Sicht somit der für die Zeit der „Wende“ und unmittelbar danach typischen Euphorie, trifft aber auf die gegenwärtige Situation - abgesehen von symbolhaften Inszenierungen wie am Görzer Bahnhofsvorplatz (Kap. 5.2) - nicht zu. Dennoch möchten wir unter Bezugnahme auf die komplizierten historischen und politischen Faktoren der Vergangenheit ein optimistisches Resümee ziehen: Grenzüberschreitende Zusammenarbeit ist auch im Untersuchungsgebiet - mit HeinTel \& W AACK $(2007$, S. 35) - ,als ein sehr langsamer Prozess zu verstehen, der im Grunde genommen gerade erst begonnen hat". Daher werden Staatsgrenzen weiterhin eine Herausforderung bleiben - nicht nur im slowenisch-italienischen Grenzraum.

\section{Literaturverzeichnis}

Ante U. (1981), Politische Geographie. Das Geographische Seminar. Braunschweig, Westermann Verlag.

Ara A. (2001), Triest - eine mitteleuropäische Stadt im Rahmen der Krise Mitteleuropas. In: Moritsch A. (Hrsg.), Alpen-Adria. Zur Geschichte einer Region, S. 471-484. Klagenfurt/ Celovec - Ljubljana/Laibach - Wien/Dunaj, Hermagoras Verlag/Mohorjeva založba.

Auprich A. (1995), Die völkerrechtliche Dimension der Triest-Frage. Dipl.-Arb., Univ. Graz, Graz.

Bahovec T. (2001), Der Zweite Weltkrieg im Alpen-Adria Raum. In: Moritsch A. (Hrsg.), Alpen-Adria.Zur Geschichte einer Region, S. 453-469. Klagenfurt/Celovec - Ljubljana/ Laibach - Wien/Dunaj, Hermagoras Verlag/Mohorjeva založba.

Bratulić J. (Hrsg.) (1993), Istra. Atlas s turističkim i poslovnim vodičem [Istrien. Atlas mit touristischem und geschäftlichem Führer]. Zagreb, Naklado Zadro.

BRAUn M. (2009), 24 Stunden geöffnet. Slowenisch-italienische Grenzerfahrungen. - www.taz. de/1/politik/europa/artikel/1/24-stunden-geoeffnet/ (Zugriff Dezember 2009)

Bufon M. (1993), Cultural and Social dimensions of borderlands: the case of the Italo-Slovene border landscape. In: GeoJournal, 30, S. 235-240. 
Bufon M. (1996), Slovenia - a Central European Border Country. In: Gosar A. (Hrsg.), Slovenia: a Gateway to Central Europe, S. 42-51. Ljubljana, Ass. of the Geographical Societies of Slovenija.

Bufon M. (2003), Cross-border cooperation in the Upper Adriatic. In: Anderson J., O’Dowd L., Wilson T.M. (Hrsg.), New borders for a changing Europe. Cross-border cooperation and governance, S. 177-198. London, Frank Cass Publ.

Castro D. (1982), La questione di Trieste, 2 Bde. Trieste, Lint Editoriale Associati.

ČEde P., FleCK D., Lieb G.K. (2007), Istrien - hundert Jahre nach Norbert Krebs. In: Mitt. d. Österr. Geogr. Ges., 149, S. 133-156.

Čede P., Steinicke E. (2007), Ghost towns in den Ostalpen. Das Phänomen der Entvölkerung im friulanischen Berggebiet (Italien). In: Geographica Helvetica, 62/2, S. 93-103.

CoOperazione territoriale europea/Europsko teritorialno sodelovanje (2010), Programma per la cooperazione transfrontaliera Italia-Slovenia/Program čezmejnega sodelovanja Slovenija-Italija 2007-2013. - http://www.ita-slo.eu (Zugriff April 2010)

Dante Alighieri Gesellschaft Klagenfurt (2008), Die Eisenbahn von Cividale nach Caporetto. - http://dante-alighieri.de/index.php? option $=$ com_content $\&$ task $=v i e w \& i d=994 \&$ ltemid $=5$ (Zugriff Jänner 2010)

Drozg V. (2008), Slowenische Städte. In: Albrecht V., Drozg V. (Hrsg.), Slowenien. Transformationen und kleinräumige Vielfalt. Natur - Raum - Gesellschaft, Bd. 5, S. 282-302. Frankfurt am Main, Inst. f. Humangeogr. d. Univ. Frankfurt.

DRŽAVNI ZAVOD ZA STATISTKU, Volkszählungsergebnisse verschiedener Jahre. - http://www.dzs. $h r$ (Zugriff Jänner 2009)

Dultinger J. (1985), Die „Erzherzog Johann-Bahn“. Erste Eisenbahnverbindung der Reichshaupt- und Residenzstadt Wien mit der Stadt und dem Adriahafen Triest. Rum, Verlag Dr. Rudolf Erhard.

Duroselle J.B. (1966), Le conflict de Trieste, 1943-1954. Brüssel, Éditions de l'Institut de Sociologie de l'Université Libre de Bruxelles.

Eicher H. (2009), Kärnten - deine Wege. Die Entwicklung der Verkehrsinfrastruktur in Kärnten. Klagenfurt, Verlag Johannes Heyn.

FABER E. (1995), Litorale Austriaco. Das österreichische und kroatische Küstenland 1700-1780 (= Schriftenreihe d. Historischen Inst., 5; Veröff. d. Steiermärkischen Landesarchives, 20), Trondheim - Graz, Verlag Reprosentralen, Universitetet i Trondheim - Adresseavisen.

Faber-Neubauer E. (1993), Die Entwicklung des Österreichischen und Kroatischen Küstenlandes zum „Litorale Austriaco“ 1700-1780. Separation und Einheit. Diss., Univ. Graz, Graz.

FridL J. et al. (2001), National Atlas of Slovenia. Ljubljana, Rokus Publishing House.

FRIDRICH C. (2003), Kooperation versus Abgrenzung auf lokaler Ebene: Fallstudie österreichischslowakisches Grenzgebiet. In: Mitt. d. Österr. Geogr. Ges., 145, S. 95-118.

Gosar A., JeršIČ M. (1999), Slowenien. Reiseführer. Lubljana, Založba Mladinska knjiga.

Gosar L., Roblek I. (2001), Die Zukunft des ländlichen Raumes in Slowenien. In: Mitt. d. Österr. Geogr. Ges., 143, S. 131-148.

Heintel M., WaAck C. (2007), Von Visionen und Zwängen. Grenzüberschreitende Zusammenarbeit an den Binnen- und Außengrenzen der EU im östlichen Europa. In: Geogr. Rundschau, 39/3, S. 28-35.

Hilpert M., KräUSSLICH B. (2007), Slowenien. Bericht über die wirtschaftliche Transformation regionaler und sektoraler Entwicklungspotenziale. In: Europa regional, 15/1, S. 38-48.

IstituTO NAZIONALE DI STATISTICA, Volkszählungsergebnisse verschiedener Jahre (ISTAT - Ufficio Regionale per la Friuli-Venezia Giulia). - http://www.istat.it (Zugriff Jänner 2009)

IstriaNet (1998), Il treno Trieste - Parenzo (La Parenzana). - http://www.istrianet.org/istria/ navigation/land/parenzana/index.htm (Zugriff Jänner 2010) 
JoRDAN P. (2006), Das Problem der ausgeprägten regionalen Disparitäten im östlichen Europa. In: Hıтz H. (Hrsg.), Europa neu denken lernen. Möglichkeiten und Ansätze für ein Lernen über und ein Denken für Europa (= Materialien z. Didaktik d. Geogr. u. Wirtschaftskunde, 19), S. 119-133. Wien.

JURIČ I. (1996), Koper - maritime gateway to Central Europe. In: Gosar A. (Hrsg.), Slovenia: a Gateway to Central Europe, S. 33-41. Ljubljana, Ass. of the Geographical Societies of Slovenija.

Keller L., Förster K. (2007), 1x1 der Alpen. 101 Regionen von Monaco bis Wien. Innsbruck, Innsbruck Univ. Press.

Klemenčič V., Bufon M. (1991), Geographic problems of frontier regions: The case of the Italo-Yugoslav border landscape. In: Rumley D., Minghi J.V. (Hrsg.), The Geography of Border Landscapes, S. 86-103. London, Routledge.

K. K. Statistische Zentralkommission (Hrsg.) (1918), Spezialortsrepertorium der Österreichischen Länder, Österreichisch-Illyrisches Küstenland, 7, Wien.

Krebs N. (1961), Die Ostalpen und das heutige Österreich. Eine Länderkunde. 2. Bd.: Regionaler Teil, 3. Aufl. Darmstadt, Wiss. Buchges.

LANGER J. (2001), Towards a conceptualization of border: The Central European experience. In: Eskelinen H., LitKanen I., OKsa J. (Hrsg.), Curtains of iron and gold - restructuring borders and scales of interaction, S. 25-42. Aldershot, Ashgate.

LAUŠIĆ A. (1987), Uzroci i oblici iseljavanja iz Istre nakon drugog svjetskog rata [Gründe und Merkmale der Abwanderung aus Istrien nach dem Zweiten Weltkrieg]. In: Zapošljavanje i udruženi rad, 12, 3, S. 369-387.

Lichtenberger E. (2005), Europa. Geographie-Geschichte-Wirtschaft-Politik. Darmstadt, Wiss . Buchges.

Marušić B. (2002), Das Österreichische Küstenland von der Mitte des 18. Jahrhunderts bis zum Jahr 1848. In: KrahwinKLER H. (Hrsg.), Staat - Land - Nation - Region. Gesellschaftliches Bewusstsein in den österreichischen Ländern Kärnten, Krain, Steiermark und Küstenland 1740 bis 1918, S. 195-211. Klagenfurt/Celovec - Ljubljana/Laibach - Wien/Dunaj.

Medaković D., Milošević D. (1987), Chronik der Serben in Triest. Belgrad, Verlag Jugoslovenska Revija.

Mestna obČina Nova Gorica (Hrsg.) (2006), Sabotin - park miru. Turistična karta 1:25.000 [Sabotin - Friedenspark. Touristische Karte 1: 25.000]. Ljubljana, Geodetski Inštitut Slovenije.

Mission opérationelle transfrontalière (2009), Gorizia-Nova Gorica. - www.espaces-transfrontaliers.org/en/conurbations/ (Zugriff Dezember 2009)

Moritsch A. (Hrsg.) (2001), Alpen-Adria. Zur Geschichte einer Region. Klagenfurt/Celovec Ljubljana/Laibach - Wien/Dunaj, Hermagoras Verlag/Mohorjeva založba.

Moritsch A. (2001), Dem Nationalstaat entgegen (1848-1914). In: Moritsch A. (Hrsg.) (2001), Alpen-Adria.Zur Geschichte einer Region, S. 339-405. Klagenfurt/Celovec - Ljubljana/ Laibach - Wien/Dunaj, Hermagoras Verlag/Mohorjeva založba.

NeĆAK D. (2001), Die Alpen-Adria Region 1945 bis 1991. In: Moritsch A. (Hrsg.) (2001), Alpen-Adria.Zur Geschichte einer Region, S. 485-516. Klagenfurt/Celovec - Ljubljana/ Laibach - Wien/Dunaj, Hermagoras Verlag/Mohorjeva založba.

NeJAŠMIĆ J. (1995), Hauptmerkmale der kroatischen Auswanderung 1880-1991. In: BudAK N. et al. (Hrsg.), Kroatien. Landeskunde - Geschichte - Kultur - Politik - Wirtschaft - Recht (= Österr. Osthefte, Sonderbd., 13), S. 97-107. Wien - Köln - Weimar, Böhlau Verlag.

Oberegger E. (2006), Eisenbahnhafen Triest. - http://www.members.al .net/edzelenzyklopaedie/ e-hafen_triest.htm (Zugriff Februar 2009) 
Palacio L. (2006), Letno poročilo o dejavnostih Evrsopske koordinatorke: Prednostni projekt št. 6 Lyon - Torino - Milano - Trst - Ljubljana - Budimpešta [Jährlicher Fortschrittsbericht der europäischen Koordinatoren: Vorteile des Projekts Nr. 6 Lyon - Turin - Mailand - Triest - Laibach - Budapest]. - http://ec.europa.eu/ten/transport/coordinators/ doc/2006_07_pp06_sl.pdf (Zugriff Jänner 2010)

Paschinger H. (1955), Triest als wirtschafts- und verkehrsgeographisches Problem. In: Verhandlungen des Deutschen Geographentages Essen 1953, 29, S. 239-246.

Pirjevec J. (2001), Die Alpen-Adria Region 1918 bis 1939. In: Moritsch A. (Hrsg.) (2001), Alpen-Adria.Zur Geschichte einer Region, S. 431-452. Klagenfurt/Celovec - Ljubljana/ Laibach - Wien/Dunaj, Hermagoras Verlag/Mohorjeva založba.

PoHL H.D. (2005), Sprachen und Sprachinseln im südalpinen Raum - ein Überblick. In: Europa ethnica, 62, S. 91-100.

Ravbar M., Klemenčič V. (1993), Current Problems of Regional Development of Slovenia. In: Horváth G. (Hrsg.), Development Strategies in the Alpine-Adriatic Region, S. 143-163. Pécs, Centre of Regional Studies, Hungarian Academy of Sciences.

Rener T. (Hrsg.) (2004), Čezmejni programi med Slovenijo in Italijo. Programmi transfrontalieri fra la Slovenia e l'Italia. Ljubljana, Agencija Republike Slovenije za regionalni razvoj.

Republik Slowenien (Hrsg.) (2009), Fakten über Slowenien. Ljubljana, Kommunikationsamt der Regierung der Republik Slowenien.

Rother K., Tichy F. (2008), Italien. Wissenschaftliche Länderkunden, 2. Aufl., Darmstadt, Wiss. Buchges.

Rumpler H. (2001), Verlorene Geschichte. Der Kampf um die politische Gestaltung des AlpenAdria-Raumes. In: Moritsch A. (Hrsg.) (2001), Alpen-Adria. Zur Geschichte einer Region, S. 517-569. Klagenfurt/Celovec - Ljubljana/Laibach - Wien/Dunaj, Hermagoras Verlag/Mohorjeva založba.

SAbotin Park Miru (2009), - http://www.sabotin.net (Zugriff Dezember 2009)

SLovenSKe ŽEleznice (2010), Vozni red po relacijah: Ljubljana - Pivka - (Ilirska Bistrica) - Sežana [Fahrplan für die Verbindungen: Laibach - Pivka - (Ilirska Bistrica) - Sežana] - http:// www.slo-zeleznice.si/sl/potniki/vozni-redi/vozni-red-po-relacijah (Zugriff Jänner 2010)

Statistični uRad Republike Slovenise, Volkszählungsergebnisse verschiedener Jahre. - http:// www.stat.si (Zugriff Jänner 2009)

Steinicke E. (1991), Friaul. Bevölkerung und Ethnizität (= Innsbrucker Geogr. Studien, 19). Innsbruck, Selbstverlag d. Inst. f. Geogr. d. Univ. Innsbruck.

Strasser K., Waitzbauer H. (1999), Über die Grenzen nach Triest: Wanderungen zwischen Karnischen Alpen und Adriatischem Meer. Wien - Köln - Weimar, Böhlau Verlag.

StuhlPfarRer K. (1996), Adriatisches Küstenland 1943-1945: Forschungsresultate und Forschungsperspektiven. In: Zeitgeschichte, 23, 3-4, S. 63-71.

VALDEvit G. (1986), La questione di Trieste 1941-1954. Milano, Franco Angeli.

ZuPANČIČ J. (2002), Grenzüberschreitende Pendelwanderung aus Slowenien nach Österreich und Italien. In: Mitt. d. Österr. Geogr. Ges., 144, S. 145-157. 